\title{
A review of Salmonella enterica with particular focus on the pathogenicity and virulence factors, host specificity and antimicrobial resistance including multidrug resistance
}

\author{
Saleh Mohammed Jajere
}

\begin{abstract}
Department of Veterinary Public Health and Preventive Medicine, Faculty of Veterinary Medicine, University of Maiduguri, PMB 1069, Maiduguri, Borno State, Nigeria.

Corresponding author: Saleh Mohammed Jajere, e-mail: drmsjajere@unimaid.edu.ng Received: 19-12-2018, Accepted: 11-02-2019, Published online: 06-04-2019
\end{abstract}

doi: 10.14202/vetworld.2019.504-521 How to cite this article: Jajere SM (2019) A review of Salmonella enterica with particular focus on the pathogenicity and virulence factors, host specificity and antimicrobial resistance including multidrug resistance, Veterinary World, 12(4):504-521.

\begin{abstract}
Salmonella genus represents the most common foodborne pathogens frequently isolated from food-producing animals that is responsible for zoonotic infections in humans and animal species including birds. Thus, Salmonella infections represent a major concern to public health, animals, and food industry worldwide. Salmonella enterica represents the most pathogenic specie and includes $>2600$ serovars characterized thus far. Salmonella can be transmitted to humans along the farm-to-fork continuum, commonly through contaminated foods of animal origin, namely poultry and poultry-related products (eggs), pork, fish etc. Some Salmonella serovars are restricted to one specific host commonly referred to as "host-restricted" whereas others have broad host spectrum known as "host-adapted" serovars. For Salmonella to colonize its hosts through invading, attaching, and bypassing the host's intestinal defense mechanisms such as the gastric acid, many virulence markers and determinants have been demonstrated to play crucial role in its pathogenesis; and these factors included flagella, capsule, plasmids, adhesion systems, and type 3 secretion systems encoded on the Salmonella pathogenicity island (SPI)-1 and SPI2, and other SPIs. The epidemiologically important non-typhoidal Salmonella (NTS) serovars linked with a high burden of foodborne Salmonella outbreaks in humans worldwide included Typhimurium, Enteritidis, Heidelberg, and Newport. The increased number of NTS cases reported through surveillance in recent years from the United States, Europe and low- and middle-income countries of the world suggested that the control programs targeted at reducing the contamination of food animals along the food chain have largely not been successful. Furthermore, the emergence of several clones of Salmonella resistant to multiple antimicrobials worldwide underscores a significant food safety hazard. In this review, we discussed on the historical background, nomenclature and taxonomy, morphological features, physical and biochemical characteristics of NTS with a particular focus on the pathogenicity and virulence factors, host specificity, transmission, and antimicrobial resistance including multidrug resistance and its surveillance.
\end{abstract}

Keywords: Enteritidis, foodborne pathogens, Heidelberg, multidrug-resistant, pathogenicity and virulence factors, Salmonella enterica, Typhimurium.

\section{Introduction}

Salmonella represents a large genus of global public health significance and is the leading cause of foodborne illnesses responsible for thousands of deaths worldwide [1-9]. Salmonella is Gramnegative, rod-shaped bacteria, and facultative anaerobes belonging to the family Enterobacteriaceae. The genus Salmonella belongs to two broad species namely Salmonella enterica and Salmonella bongori. So far, more than 2600 serovars belonging to $S$. enterica have been described worldwide, and many of these serovars are capable of causing illnesses in both humans and animals [10]. While few variants of S. enterica namely Salmonella Gallinarum (SG) and Salmonella Pullorum (SP) are non-flagellated and

Copyright: Jajere. Open Access. This article is distributed under the terms of the Creative Commons Attribution 4.0 International License (http://creativecommons.org/licenses/by/4.0/), which permits unrestricted use, distribution, and reproduction in any medium, provided you give appropriate credit to the original author(s) and the source, provide a link to the Creative Commons license, and indicate if changes were made. The Creative Commons Public Domain Dedication waiver (http://creativecommons.org/ publicdomain/zero/1.0/) applies to the data made available in this article, unless otherwise stated. non-motile, the majority of members in the genus Salmonella are motile by peritrichous flagella. The SG and SP are associated with clinical disease in poultry, and they cause considerable economic losses - due to the replacement of infected flocks and associated treatment costs - to poultry farmers, especially in developing countries of the world [11-13]. In general, the genus has a predilection limited to the digestive tracts of both humans and animals hosts. Thus, the presence of Salmonella in other habitats such as the water, environment, and food represents fecal contamination. Recent data from the United States, European countries, and low- and middle-income countries (LMICs) indicate that Salmonella cases are the most commonly encountered cause of bacterial foodborne disease globally and hence supporting the fact that the control programs aimed at reducing the Salmonella contamination along the food chain have not been successful [14]. Consequently, there will be increased frequency and persistence of S. enterica in the intestinal tracts of food animals and this situation creates chronic or non-symptomatic carriers that continue to shed the organism in their feces. Thus, these 
carriers serve as reservoirs for future contamination and spread of Salmonella by contaminated milk, meat, eggs and other agricultural products fertilized and grown in Salmonella contaminated manure [14].

In recent years, the development of antimicrobial resistance (AMR) among foodborne pathogens such as Salmonella have been associated with an increased number of human deaths, longer duration of hospital stay, and high costs of treatment due to therapy failure. Several clones of multidrug-resistant (MDR) Salmonella have emerged during the late 1990s and early 2000s and since then, their prevalence both in humans, domestic animals and other wildlife species have expanded globally [9,15-25]. Recently, the increasing prevalence of MDR Salmonella such as resistance towards clinically important antimicrobials like fluoroquinolones and third-generation cephalosporins has become an emerging problem worldwide [16,18,26-33]. In recent years, studies on the global burden of non-typhoidal Salmonella (NTS) have shown an increasing incidence of NTS. For instance, one of these studies estimated that there are approximately 94 million cases of NTS gastroenteritis resulting in 155,000 deaths globally each year [34]. According to this study, majority of the NTS burden was found in the Southeast Asian and the Western Pacific regions [34,35].

Moreover, of the 94 million NTS cases reported [34], 80.3 million cases were estimated as foodborne origin [15]. Among the NTS, Salmonella Typhimurium (ST), Salmonella Enteritidis (SE), Salmonella Heidelberg (SH), and Salmonella Newport (SN) are the epidemiologically important NTS serotypes - with poultry and poultry derived products as important reservoir sources - and have been associated with the majority of human salmonellosis burden worldwide [5,36-40]. S. enterica is widely distributed in the environment and has been associated with a variety of infections in cattle, pigs, and birds including poultry and free-living wild birds [40-53].

Until today, Salmonella including MDR strains remains one of the leading bacterial foodborne cause of deaths especially in the LMICs [24,54]; where foods/ready-to-eat foods are prepared under less hygienic environments and fruits and vegetables are grown in farms with poor management practices. In many of these countries, these foods are sold by people who are less enlightened about the risks posed by foodborne pathogens. This review paper attempts to discuss on the historical background, nomenclature and taxonomy, morphological features, physical and biochemical characteristics of NTS with particular emphasis on the pathogenicity and virulence factors, host specificity, AMR including MDR and its surveillance.

\section{Brief History}

The first study of Salmonella began during the early $19^{\text {th }}$ century by Eberth, who first recognized the organism and subsequently Gaffky isolated the bacillus responsible for human typhoid fever [55]. Thereafter, in 1885 Theobald Smith together with Daniel Elmer Salmon discovered and isolated Salmonella from the intestines of pigs infected with classical swine fever (hog cholera). During this period, they thought the bacterium was the etiological agent of hog cholera $[55,56]$. Later, the bacterial strain was named Salmonella after Dr. Daniel Elmer Salmon, an American pathologist who has worked together with Smith [57]. In recent years, the issue of nomenclature of the genus Salmonella has been complex, controversial, and still remains subject of debate [57]. At present, most Salmonella reference centers in the world including the Centers for Disease Control (CDC) adopt the nomenclatural system of Salmonella as recommended by the World Health Organization (WHO) [58]. This nomenclatural system classifies the genus Salmonella into two species based on differences in their $16 \mathrm{~S}$ rRNA sequence analysis. These two broad species included $S$. enterica (type species) and S. bongori [57].

\section{Nomenclature/Taxonomy}

On the basis of biochemical properties and genomic relatedness, the $S$. enterica is further classified into six subspecies [59]. These subspecies in the nomenclature are denoted by Roman numerals: I. S. enterica subsp. enterica; II. S. enterica subsp. salamae; III. S. enterica subsp. arizonae; IIIa. S. enterica subsp. diarizonae; IV. S. enterica subsp. houtenae; and V. S. enterica subsp. indica. Of all the subspecies of Salmonella, the S. enterica subsp. enterica (I) is the most common and is found predominantly associated with mammals and attributes about $99 \%$ of Salmonella infections in humans and warm-blooded animals. On the other hand, the other five S. enterica subspecies and $S$. bongori are rare in humans and are mainly found in cold-blooded animals and the environment [60].

The Kauffman and White classification system is another system in addition to the classification of subspecies based on phylogeny $[61,62]$. This scheme classifies Salmonella further into serotypes on the basis of three major antigenic determinants including somatic $(\mathrm{O})$, Capsular $(\mathrm{K})$, and flagella $(\mathrm{H})$ [60]. The somatic $(\mathrm{O})$ antigen is located at the outer bacterial cell membrane and is heat-stable and forms the oligosaccharide component of the lipopolysaccharide (LPS) of the bacterial cells. More than one $\mathrm{O}$ antigen could be expressed by a specific Salmonella serotype. The heat-labile $\mathrm{H}$ antigens are involved in the activation of host immune responses and are mainly found in the bacterial flagella. Majority of Salmonella spp. possessed two different genes, which encode for the flagellar proteins. These bacteria could be diphasic (phase I and II), which means that they possess the unique ability to express only one protein at a time. The phase I H antigens which are responsible for 
immunological identity could be expressed by some serotypes, whereas phase II antigens are non-specific antigens and could be found in many other serotypes [63]. Finally, the surface $\mathrm{K}$ antigens are rarely found among the majority of Salmonella serotypes and are heat-sensitive polysaccharides mainly located at the bacterial capsular surface. A subtype of $\mathrm{K}$ antigen, the virulence (Vi) antigens are found only in serotypes Paratyphi C, Dublin, and Typhi. "Serovar" a term that is synonymous to serotype has been used commonly in the literature. The subspecies in the naming of a particular Salmonella serotype is usually omitted. For instance, $S$. enterica subspecies enterica serotype Typhi is normally shortened to Salmonella ser. Typhi or $S$. Typhi in literature [60]. So far, over 2500 serotypes have been identified (each having a unique combination of somatic $\mathrm{O}$ and flagellar $\mathrm{H}_{1}$ and $\mathrm{H}_{2}$ antigens), of which $>50 \%$ of these serotypes belong to the $S$. enterica subspecies. These serotypes account for the majority of Salmonella infections in humans [64].

\section{Morphology, Bacteriological Culture, and Isolation Procedures}

The size of Salmonella is $0.2-1.5 \times 2-5 \mu \mathrm{m}$, and they are facultative anaerobes, rod-shaped, and Gramnegative bacilli of the family Enterobacteriaceae. With the exception of SG and SP, members of the genus Salmonella are motile by the means of flagella. Members of this genus have the ability to metabolize nutrients by both respiratory and fermentative pathways referred to as chemoorganotrophic [65]. Majority of the Salmonella serovars produce hydrogen sulfide with the exception of few serovars such as $S$. Paratyphi A, and $S$. Choleraesuis. Most members of the genus do not ferment lactose. This important unique property has been used for the development of a variety of selective and differential media for the culture, isolation, and presumptive identification of Salmonella [66]. These media included SalmonellaShigella agar (SS), brilliant green agar (BGA), xylose lysine deoxycholate (XLD) agar, Hektoen enteric (HE) agar, MacConkey agar, lysine iron agar (LIA), and triple sugar iron (TSI) agar [67,68]. Typically, isolation of Salmonella from swabs, food, and other environmental samples utilizing the traditional or conventional culture method involves multiple steps of pre-enrichment, selective enrichment, and growth on selective and differential media for the purpose of enhancing the sensitivity of the detection methods [67]. It involves an initial non-selective pre-enrichment of a defined volume of the sample, followed by a selective enrichment step, plating onto selective agars, and then biochemical and serological confirmation of suspect presumptive colonies [1]. In recent years, several regulatory agencies such as association of official analytical chemists, the US food and drug administration (FDA) agency, food safety and inspection service of U.S. Department of Agriculture (USDA), and
International Organization for Standardization (ISO) have standardized different approaches of Salmonella enrichment utilizing its unique biochemical physical properties. The current ISO standard method, ISO 6579:2002 has been adopted by many Salmonella reference centers and is essentially similar to other standard detection methods for Salmonella standardized by other regulatory agencies [69].

Briefly, the conventional cultural isolation method consists of pre-enrichment of samples in buffered peptone water (or lactose broth) for recovering of sublethally injured Salmonella cells while inhibiting the growth of other competing bacterial flora followed by a selective enrichment in Rappaport-Vassiliadis (Soya base) and Muller-Kauffmann TetrathionateNovobiocin containing two or more inhibitory reagents that allow continuous growth of Salmonella while suppressing the growth and propagation of other bacteria $[68,69]$. Subsequently, the incubated selective enrichment broth are streaked on selective media such as SS, BGA, bismuth-sulfite agar, HE agar, and XLD agar. These selective media allow the growth of Salmonella organism, while at the same time suppressing the propagation of other bacteria. The colors with the coliforms formed on these media are used for differentiating colonies of Salmonella serotypes. For instance, $S$. Typhi on SS appears as colorless colonies with a black center. Typically, Salmonella colonies on XLD appear as colorless colonies with black centers, while spherical moist colonies with purple color on BGA [69]. The resulting presumptive colonies isolated on plating media are then incubated in both TSI and LIA followed by tests including urease test and other additional tests for urease negative cultures [1]. Typical Salmonella culture conforming with unique reactions is further subjected to biochemical and serological identification tests [1].

\section{Physical and Biochemical Characteristics}

Salmonella is non-fastidious because they have the ability to grow and multiply under various environmental conditions outside the living hosts. Although they can grow in the presence of $0.4-4 \%$ of sodium chloride, they do not require sodium chloride for growth. Majority of serotypes thrive and grow at a temperature range of $5-47^{\circ} \mathrm{C}$ with an optimum of $32-35^{\circ} \mathrm{C}$. However, some few serotypes can grow at a much wider temperature as low as $2-4^{\circ} \mathrm{C}$ or as high as $54^{\circ} \mathrm{C}$ [70]. Salmonella is sensitive to heat and is often killed at temperatures of $70^{\circ} \mathrm{C}$ or above. The $\mathrm{pH}$ necessary for the growth of Salmonella ranges from 4 to 9 , with an optimum range between 6.5 and 7.5. Although Salmonella can survive in $<0.2$ water activity such as in dried foods, they require high water activity of between 0.99 and 0.94 for their survival. The growth of Salmonella is completely inhibited at $\mathrm{pH}<3.8$, the water activity of $<0.94$ and temperatures of $<7^{\circ} \mathrm{C}$ [70]. While almost all serotypes do not produce indole, hydrolyze urea, and deaminate 
phenylalanine or tryptophan, most serotypes readily reduce nitrate to nitrite, ferment a variety of carbohydrates with acid production, and are negative for Voges-Proskauer reaction [65]. With the exception of $S$. enterica subsp. arizonae and $S$. subsp. diarizonae, most serotypes utilize arginine, ornithine, decarboxylate lysine and hydrogen sulfide. Similarly, most serotypes utilize citrate with the exception of some few serovars of $S$. Choleraesuis, $S$. Typhi, and $S$. Paratyphi A [65]. While most serovars do not utilize lactose, dulcitol is generally utilized by all serovars with the exceptions of $S$. enterica subsp. arizonae (IIIa) and $S$. enterica subsp. arizonae (IIIb) [65].

\section{Pathogenicity and Virulence Factors}

The key virulence traits and factors of $S$. enterica such as invasion or intracellular replication inside host's cells have been approached by various methods such as screening for attenuated mutants, and this has resulted in the identification of many single genes that contribute to the virulence traits at the molecular cellular levels [71]. Many virulence factors have been demonstrated to play variety of roles in the pathogenesis of Salmonella infections. These factors included flagella, capsule, plasmids, adhesion systems, and type 3 secretion systems (T3SS) encoded on the Salmonella pathogenicity island (SPI)-1 and SPI-2 and other SPIs $[72,73]$. While other studies revealed that $S$. enterica like many other enteropathogenic bacteria produce a variety of virulence determinants, some of which are part of the adhesion systems including adhesins, invasins, fimbriae, hemagglutinins, exotoxins, and endotoxins [74]. These factors singly or in combination with others allow the Salmonella to colonize its host through attaching, invading, surviving, and bypassing the host's defense mechanisms such as the gastric acidity, gastrointestinal proteases, and defensins as well as aggressins of the intestinal microbiome [14].

Salmonella pathogenicity islands (SPIs) are gene clusters located in certain areas of the chromosomes in the bacterial cells that are responsible for encoding the various virulence factors (adhesion, invasion, toxin genes, etc.) [75]. These gene clusters or SPIs can be located on either the plasmid or the chromosomes; compared with the surrounding region they tend to have a variable composition of $\mathrm{G} / \mathrm{C}$ and are flanked by repeat sequences [76]. The SPIs are characterized to be often associated with transfer RNA (tRNA) and mobile genetic elements such as transposons or phage genes, and they tend to have a base composition entirely different from the core genomes [77]. To date, several SPIs have been reported for different Salmonella serovars by different authors with SPI-1 to -5 being the most commonly observed in many serovars of Salmonella and others less commonly distributed among the serovars $[75,78,79]$.

In general, the SPIs play different roles in the pathogenesis and virulence of Salmonella. Briefly, the SPI-1 is required for the invasion of host cells and induction of macrophage apoptosis, SPI-2 for systemic infections and replication within macrophages, SPI-3 for survival in macrophages and also required for growth of Salmonella in low-magnesium environments, SPI-4 for harboring genes responsible for toxin secretion and apoptosis as well as intramacrophage survival, SPI-5 for clustering genes that encode multiple T3SS effector proteins, and SPI-6 has been found in response to external stimuli to transport proteins into the cellular environment or host cells [75,79-84]. In one of these studies [84], the authors reported genetic variations among SPI-1, SPI-3, and SPI-5 while the other two, SPI-2 and SPI-4, were reported to be well conserved among 13 Salmonella serovars isolated from various sources including warm-blooded animals (bovine, porcine, avian, and equine), environment, and human patients [84]. Furthermore, the authors also reported that all isolates within the same serovar are identical with respect to the five SPIs tested (SPI-1, SP1-2, SPI-3, SPI-4 and SPI-5) with the exception of those from the ST [84].

Earlier studies reported that most strains of Salmonella serovars possessed serotype-specific virulence plasmids. These are plasmid-associated virulence characterized by low-copy-number plasmids (usually one to two copies per cell), and depending on the serovar, its size ranges from 50 to $100 \mathrm{~kb}[80,85]$. In each of these plasmids, there is a Salmonella plasmid virulence (spv) locus, where its expression in Salmonella organisms has been reported to be important for multiplication of Salmonella within the reticuloendothelial system including liver cells and the spleen $[80,86]$. In addition to serotype-associated virulence plasmids, other plasmids are likely to contribute or confer some resistance observed among Salmonella serovars [87]. Other authors reported several different plasmids that are likely responsible for the virulence of serovars such as SH, S. Kentucky, and ST $[88,89]$.

Production of both endotoxins and exotoxins has also been attributed to confer pathogenicity among Salmonella serovars. The former has been found to elicit a wide range of biological responses, whereas the latter comprising enterotoxins and cytotoxins is associated with killing of the mammalian cells [90]. In one of the studies investigating the production of cytotoxins among Salmonella serovars, the authors reported the production of heat-labile trypsin-sensitive cytotoxins with various molecular masses among different serovars including ST (70 kDa), $S$. Choleraesuis (78 kDa), and $S$. Typhi (56 kDa) [90]. In addition, other studies reported two other types of exotoxins namely Salmonella enterotoxin and salmolysin encoded respectively by the stn and slyA genes. These two exotoxins have been identified among serovars Typhi, Enteritidis, and Typhimurium [91]. One study [92] attempted to sequence and clone the salmolysin (product of slyA gene) in order to determine its hemolytic property. The authors found out that, the deduced 
sequence of the salmolysin showed significant homology with regulatory proteins. Therefore, the authors concluded that the hemolytic property of salmolysin could be due to a regulatory event affecting the expression of an Escherichia coli hemolysin (HylE) rather than hemolytic activity from the salmolysin itself [92]. Twenty five ST strains recovered from clinical specimens including blood, cerebrospinal fluid (CSF), urine, and feces were studied for markers of virulence [93]. It was found that three of the five isolates from blood, all isolates from both CSF and urine and only two of the fifteen isolates from the feces demonstrated positive fluid accumulation in the rabbit ileal loop. As detected by the latex agglutination and immuno dot blot tests, all the strains positive for the fluid accumulation produced an enterotoxin principle, antigenically related to the cholera family of enterotoxins. Low $\mathrm{LD}_{50}$ indicating high virulence was exhibited by all the five isolates from the blood samples, all strains from CSF and one of the two urine strains. This study revealed that some strains of ST are more virulent and produced more enterotoxins as compared to the low virulent strains. The virulent strains invaded the intestinal mucosa and led to extra-intestinal manifestations, whereas the low virulent strains were confined to the intestine and caused mild/moderate gastroenteritis [93].

In an attempt to investigate the production of toxins and their role in the pathogenesis of bloody diarrhea caused by Shigella and Salmonella from children suffering with bloody diarrhea, human epithelial cells from colon carcinoma (HT-29), Chinese hamster ovary cells (CHO), and kidney fibroblast from rhesus monkey (Vero) were used to detect the cytotoxins [94]. It was found that Salmonella strains recovered from the diarrheic children produced cytotoxins and enterotoxins, which could play a role in the intestinal disease. Over $50 \%$ of the Salmonella strains caused elongation and some strains causing rounding of $\mathrm{CHO}$ cells, about $20 \%$ of the strains resulted in rounding of HT-29 cells and $>60 \%$ of the Salmonella isolates caused rounding of the Vero [94]. The cytotoxigenicity of different $S$. enterica serovars was also studied on the MadinDarby Bovine Kidney and Vero cell lines [95]. The serovars tested comprised Typhimurium, Nchanga, Newport, Virchow, Bovismorbificans, Seftenberg, Weltevreden, and Indiana. The authors revealed that all the strains exhibited cytotoxic activity on both the cell lines. However, the cytotoxic activity varied greatly among the serovars and was dose-dependent. Another study [96] reported a positive reaction for enterotoxin production among $76 \mathrm{SE}, 3 \mathrm{~S}$. Virchow, and $1 S$. Braenderup strains following screening for enterotoxicigenicity using the $\mathrm{CHO}, \mathrm{Y} 1$ adrenal, and Vero and HeLa cell tests. In this study, it was found that $\mathrm{CHO}$ cells were more sensitive compared to the Vero and Y1 adrenal cells. Overall, this study found that $79(98.75 \%)$ of the investigated strains were producers of enterotoxins as detected from their biological assays. The authors argued that high frequency of enterotoxin production by the Salmonella strains might be related to the fact that most Salmonella species when present in the gastrointestinal tracts of their hosts are associated with diarrheal disease.

Another important virulence factor for Salmonella is HylE protein, which is a product of hylE gene [97]. The HylE toxin like many other pore-forming toxins is an important virulence factor among the majority of the bacteria including Salmonella [98]. They are important in that they probably play key roles in the pathogenesis of systemic salmonellosis and have been used recently in the sub-serovar level typing $[99,100]$. Some proteomic studies have demonstrated that production of HylE by Salmonella and other enteric bacteria plays a crucial role in the pathogenesis of $S$. Typhi [97]. Another study [101] investigated the HylE patterns of 175 strains of different $S$. enterica serovars recovered from different animal sources and places utilizing 11 different blood agar media made with either nonwashed horse/sheep erythrocytes or with washed erythrocytes of cattle, sheep, horse, goat, rabbit, guinea pig, and human $\mathrm{A}, \mathrm{O}$, and $\mathrm{B}$ groups. The findings revealed that all host restricted $S$. enterica serovars, namely SG, $S$. Anatum, $S$. Abortusequi, and $S$. Paratyphi B could be divided into different HylE types based on their inability to produce hemolysis on one or more types of the blood agar utilized. While, other strains of all the zoonotic Salmonella serovars induced hemolysis on all the nine types of blood agar made of washed erythrocytes [101]. Further, it was revealed that none of the 175 serovars could produce hemolytic colonies on the blood agar made of non-washed sheep/horse erythrocytes. With the exception of $S$. Abortusequi, the most common HylE pattern observed among all the other studied serovars was HylE type I (lysing all types of washed erythrocytes). In the same study, it was shown that the hemolytic strains of $S$. Abortusequi possessing hemolytic activity against sheep erythrocytes were more invasive but had lesser ability to survive in sheep mononuclear cells as compared to the non-hemolytic strains [101].

To investigate the hemolytic potential of SG strains (94 strains), both phenotypic and genotypic methods including amplification of the HylE gene $(\operatorname{cly} \mathrm{A})$ and cytolysin gene $(\operatorname{sly} \mathrm{A})$ were utilized in an attempt to determine their role in HylE production among the studied strains [99]. From this study, the researchers found that the SG strains produced two kinds of hemolysis namely, beneath the colony hemolysis or contact hemolysis $(\mathrm{BCH})$ and clear zone hemolysis $(\mathrm{CZH})$. Hemolysis was observed in blood agar made from the blood of sheep, goat, cattle, buffalo, guinea pig, fowl, horse, and human $\mathrm{A}, \mathrm{B}, \mathrm{AB}$, and $\mathrm{O}$ groups. While slyA gene could be amplified uniformly regardless of the hemolytic potentials and patterns of the studied strains, the clyA gene was not detected in any of the 94 studied strains. It was suggested from this study that the hemolytic activity - comprising the $\mathrm{BCH}$ and $\mathrm{CZH}$ - observed among the SG strains 
might not be due to either slyA or cly $A$ gene products. Consequently, it was concluded that some genes other than slyA and clyA might be responsible for the hemolytic activity observed in SG strains and the different hemolytic patterns observed on the different blood agar medium could be indicative of the multiplicity of HylEs among the studied SG strains. [99].

Fimbriae play an important role in the pathogenesis of Salmonella, and recently it has been shown to represent a source of diversity among Salmonella serovars [102,103]. Fimbriae represent the most common adhesion systems, which are differentially expressed and are found in specific patterns among each serovar $[104,105]$. They mediate adhesion of Salmonella to hosts' cells, food, stainless steel, etc., and have been implicated in a variety of other roles namely biofilm formation, seroconversion, hemagglutination, cellular invasion, and macrophage interactions $[73,102,106-110]$. The fimbrial systems are normally organized in gene clusters of 4 to 15 genes encoding for structural, assembly and regulatory proteins. With the exception of few fimbriae that are only present in specific serovars, several fimbriae are conserved among Salmonella serovars [102]. Until today, the expression, regulation, and roles played by fimbrial genes during the pathogenesis of Salmonella infections are poorly understood partly because most Salmonella fimbriae are poorly expressed during in vitro culture, which further complicates research concerning their regulations and roles [102]. A specific fimbrial gene clusters (FGCs) encodes for the assembly, structural, and sometimes regulatory proteins required for the production of the filamentous adhesive appendage on the bacterial surface [102]. The FGCs are usually composed of 4 to 15 genes $[102,106,107]$. So far, an average of 12 FGCs by strains was observed in S. enterica and in spite of harboring multiple FGCs by the genome of all Salmonella strains, only a few have been studied and characterized thus far [102]. Previous studies using mice model investigated the role of ST fimbriae in intestinal cells attachment, persistence in guts, and cecum colonization [111-113]. Furthermore, fimbriae have been demonstrated to be important determinants of host adaptation by Salmonella [114].

Flagella located on the cell surface of many bacteria including Salmonella have been known to confer pathogenicity besides conferring motility [80]. It is possessed by the majority of Salmonella serovars and can be up to 10 normally positioned at random on their cell surface [80]. One of the mechanisms employed by certain Salmonella serovars to minimize the host immune response is their ability to display flagellin phase variation, which creates phenotypic heterogeneity of the flagellar antigens [80]. However, the ability and role of flagella (motility and direction of rotation) in the pathogenesis and perhaps their role in adhesion and invasion of mammalian cells still remains unclear [80]. Other virulence factors such as surface polysaccharides may also play role in the pathogenesis of Salmonella by allowing the persistence of the bacteria in the intestinal tracts of the hosts [87]. Several studies have identified multiple mutants affecting LPS biosynthesis in Salmonella strains isolated from calves and chickens [81,115-117]. One of these studies [115], investigated the virulence in 1-day-old chicks of the LPS $r f b K, d k s A$, hupA, sipC and $c l p B$ and $r f a Y$ transductants, and $p t s C$ mutants. The researchers found that all but the pts $C$ and $r f a Y$ mutants were attenuated for virulence in chickens. While another study [116] on the LPS and ST mutants comprising $r f a K, r f a B, r f a G$, $r f b P, r f b N, r f b U, r f b H$, and $r f b A$ demonstrated that these mutants were unable to colonize the intestines of the calf. The findings from this study suggested the possible role of surface polysaccharides and cell envelope proteins as virulence factors conferring on ST the ability to colonize intestines of the calves. The LPS has been shown to confer on SE the ability to survive in the egg albumen [118].

\section{Host Specificity and Adaptation}

The host specificity of particular pathogenic Salmonella depends on the serovar's ability to adapt to the environment of its hosts. This specific ability to adapt to the host's environment is regulated by many microbial characteristics, which are responsible for the expression of clinical manifestations in specific host species [119]. Other important determinants included the infectious dose of the particular serovar, animal species infected, host's age, and immune response. It has been demonstrated that a particular mechanism making a serovar virulent for one particular animal species could make the same serovar less or even avirulent for another animal species [120]. This phenomenon is referred to as "serovar host specificity" or "serovar host adaptation." For instance, serovars Dublin and Choleraesuis, which are consistently associated with salmonellosis respectively in cattle and pigs [121]. Therefore, host adaptation or specificity is the ability of the particular organism to cause disease in a particular animal population regardless of the degree of pathogenicity it exhibits for a different animal host [119]. An example is the serovar Choleraesuis considered a pig-adapted serovar because it persists in pig populations and not because it causes the severest disease in swine compared to man [121]. It is believed that the process of host adaptation by $S$. enterica serovars involves two mechanisms namely, acquisition of novel genetic elements encoding specific virulence factors and loss of genes [119]. Serovars having host specificity which is dependent on gene deletions included Typhimurium, Enteritidis, Choleraesuis, Gallinarum, Pullorum, Abortusovis, Paratyphi C, and Dublin. Most of the earlier in vitro and in vivo studies on Salmonella host specificity and adaptation were based on the multiplication and survival of Salmonella in macrophages from a wide range of animal hosts including humans.

In a study [122] to investigate the differential adaptive evolution of Salmonella serovars, a genetic 
and functional analysis of the mannose-specific type 1 fimbrial adhesin $(\mathrm{FimH})$ was employed. The findings from this study revealed that specific mutant variants of FimH were common in host-adapted (systemically invasive) serovars. Majority of the host-adapted serovars expressed FimH variants with either one of the two phenotypes namely a significantly increased binding to mannose as seen in serovars Typhi, Paratyphi C, Dublin, some of Choleraesuis or complete loss of the mannose-binding activity as demonstrated by serovars Paratyphi B, Choleraesuis, and Gallinarum [122]. Whereas, the low-binding shear-dependent phenotype of the adhesion was found to be preserved in broad host-range (systemically non-invasive) serovars [122]. Recently acquired structural mutations could be responsible for the functional diversification of FimH observed in host-adapted Salmonella serovars. Thus, the findings suggested that activation or inactivation of mannose-specific adhesive properties in different systemically invasive serovars reflects their dynamic ability and course of adaptation to the biological environment of their specific hosts. The authors finally demonstrated that mechanisms such as point mutations, the target of positive selection, horizontal gene transfer and genome degradation could be responsible for a differential pathoadaptive evolution of some Salmonella serovars [122]. Another study demonstrated that the correlation of some phage types of ST with their hosts and marked host specificity was expressed by the phage types [123]. From this study, however, most of the studied phage types had a broad spectrum of hosts, and this may suggest a phage transfer of virulent genes between hosts eventually leading to host specificity.

Another study [124] assessed S. enterica clinical isolates sourced from humans and animals for their virulence capacities and presence of the Salmonella virulence plasmid encoding the SpvB actin cytotoxin in mice. The researchers found that all Typhimurium strains derived from animal clinical cases were demonstrated to be virulent also in mice, whereas strains derived from the human salmonellosis patients lacked this ability. It was further revealed that many of the human Typhimurium strains derived from patients with gastroenteritis lacked the Salmonella virulence plasmid in contrast to all the animal and human bacteremia strains tested [124]. Furthermore, in contrast to the Typhimurium strains derived from animals phenotypically exhibiting virulent determinants, those derived from man and harboring the Salmonella virulence plasmid were avirulent in mice [124]. These findings are suggestive of the fact that Salmonella isolates of the same serovar derived from animal salmonellosis are distinctively different from those of human origin. Consequently, these findings suggest that selective pressure within a particular host may give rise to bacterial strain variants exhibiting different pathogenicity determinants and hence varying degree of pathogenicity $[119,124]$.
Another group of researchers [125] from the United Kingdom assessed the factors influencing Salmonella host specificity in calves by characterizing the pathogenesis of different serotypes comprising SG, $S$. Dublin, $S$. Choleraesuis, and $S$. Abortusovis. The researchers revealed that through the intravenous route, serotypes Dublin and Choleraesuis were found to be highly and moderately virulent in calves respectively. Both serotypes were found virulent in calves infected orally. In contrast, it was revealed that both serotypes Gallinarum and Abortusovis were avirulent by either intravenous or oral routes [125]. The researchers concluded that these results could be suggesting that initial interactions with the intestinal mucosa by the different studied serovars do not correlate with host specificity, although crucial for the induction of bovine salmonellosis was the persistence of the serovars within tissues and their translocation through an efferent lymphatic system of the calves [125].

Similarly, another group of researchers tested the hypothesis that macrophages are a contributing factor to Salmonella host specificity [126]. Although serotype Typhimurium is closely related and shared major virulence loci with the host-specific serovar Typhi that causes disease in humans, Typhi does not cause disease in mice. No significant difference was observed in regard to the survival of the two serovars in vitro in mouse macrophage cell lines and primary murine peritoneal and bone marrow-derived macrophages after $24 \mathrm{~h}$. Findings from this study suggest that macrophages were able to distinguish serovar Typhi from Typhimurium when infected in vivo; however, no significant difference was observed after $24 \mathrm{~h}$ in vitro. These results support the fact that the differential killing by macrophages of the two studied serovars may require other intrinsic host factors [126]. In India, research on understanding the problem of host specificity of $S$. Abortusequi was conducted using five isogenic strains including aroA, htrA and aroAhtr $A$ deletion mutants, virulence plasmid-cured and wild type parent strains [127]. The strains were tested for invasion, survival and multiplication in macrophages from cattle, goat, buffalo, horse, guinea pig, and murine macrophage-like cells (J-744). With the exception of goat macrophages where invasion rate was comparatively lower, invasion of the different $S$. Abortusequi strains in the different macrophages was not significantly varied. Also revealed was the multiplication of wild type and virulence plasmid cured $S$. Abortusequi in horse macrophages and J-744 cells, suggesting that host specificity and adaptation could be due to the multiplication of Salmonella in macrophages. Overall, the findings from the study support the notion that aroA and $h t r A$ genes play crucial roles in macrophages because both the aro $A$ and $h t r A$ deletion mutants failed to survive in cattle and buffalo macrophages as well as in J-744 cells [127].

The degree of host adaptations by Salmonella serotypes varies and this affects their pathogenicity for 
human and animals hosts [128]. Host-restricted serotypes include $S$. Typhi and $S$. Paratyphi (only infect and cause clinical disease in man) and SG and SP (with only poultry as their primary hosts and cause clinical disease in these species). While serotypes such as ST and SE are host-adapted having broad host spectrum and thus, can affect both humans and a wide range of animal species (Table-1). $S$. Typhi and $S$. Paratyphi (Typhoidal strains) are highly adapted to man, and they usually cause severe typhoid syndrome/enteric fever. However, these serotypes are not usually pathogenic to animals [128]. In contrast, serotypes that are highly adapted and have preference for animal hosts may produce mild infections to severe systemic illness in man. For instance, serotypes $S$. Gallinarum and $S$. Abortusovis with poultry and sheep respectively as the primary hosts may cause very mild symptoms in human hosts, whereas $S$. Choleraesuis with swine as the primary host causes severe systemic illness in man. Similarly, $S$. Dublin, which is highly adapted to cattle as the primary host, is responsible for the systemic form of salmonellosis in humans [128]. This serotype causes high mortality in young calves, and other signs include fever, diarrhea, abortion and occasionally death may occur in adult cattle. Among the NTS, serotypes ST and SE (host-adapted) are ubiquitous affecting both man and animals. They generally cause gastroenteritis with less severity than enteric fever. They are also able to asymptomatically colonize chickens. However, studies have shown that these serotypes are capable of causing typhoid-like infections in mice and humans [129].

\section{Transmission of Salmonella}

Salmonella is ubiquitous and extremely persistent in the dry environment but also in water for periods ranging from days to several months. S. enterica serovars have varied hosts and reservoirs and can cause disease in both humans and animals. With the exception of a few serovars that are host-restricted, the majority of $S$. enterica serovars are host-adapted and hence, they can infect and cause disease in a variety of hosts [130]. In farm animals, Salmonella can cause clinical disease or subclinical infections in asymptomatic animals refer to as "carriers." For instance, an earlier study has shown that subclinical infection in hens can persist for $>22$ weeks [131]. While another study suggested that carrier pigs are an important source of contamination of the environment, other animals in the farms and carcasses at the harvesting stage [132]. These carriers are very important in the perpetuation of Salmonella transmission in the farms and environment in that they can shed the organism in their feces continuously and intermittently without manifesting any clinical signs. In a similar way, pets such as dogs and cats have been shown to harbor the organism asymptomatically and thus, could contaminate the environment and other food-producing animals by shedding the bacteria intermittently in their feces [133].

Other important means of transmission include vertical and horizontal transmission [130]. The former involves the transmission of the bacteria from parents to progeny. Vertical transmission is very important especially in poultry related Salmonella infection caused by the serovar Enteritidis that has a special affinity for the reproductive system of chickens. In this case, transmission to progeny occurs by transovarian infection when the parent birds have systemic infection leading to infection of the ovary and developing eggs in the oviducts [130]. Another means by which the serovar Enteritidis get access to eggs is by migration from the cloaca to the reproductive organs. Accumulating body of evidence also suggests that Salmonella can be transmitted vertically from dam to fetus in utero in dairy cattle [134]. On the other hand, horizontal transmission occurs either through the feco-oral or aerogenous routes. Introduction of Salmonella into herds can also occur through new purchase and infected pigs; and there is evidence of its spread by fomites, contaminated drinking water, contaminated feeds and dirty feeders, asymptomatic carriers and feces from clinically infected animals in the farm [130].

Pests such as rodents (mice and rats), flies and cockroaches play an important role in the transmission of Salmonella from one farm building and facilities to another as well as its perpetuation [130]. Rodents are important vectors and reservoirs of Salmonella; they can carry the bacteria in their intestinal tracts asymptomatically without any clinical disease [52]. They have been associated with frequent contamination of feeds, water and stored grains in the farms and can acquire the bacteria mainly from the feces of sick or

Table-1: Host-specificity and disease syndromes of the representative serotypes [128].

\begin{tabular}{lll}
\hline Salmonella serogroup/serotype & Hosts & Disease \\
\hline D/Typhi & Humans & Septicemia, fever \\
A, B, C/Paratyphi & Humans & Septicemia, fever \\
B/Typhimurium & Humans, cattle, swine, horses, sheep, Gastroenteritis, septicemia, fever \\
& poultry, wild rodents \\
D/Enteritidis & Humans, poultry, wild rodents & Gastroenteritis, septicemia, fever \\
D/Dublin & Cattle, swine, sheep & Gastroenteritis, abortion, septicemia, fever \\
B/Derby & Birds, swine & Gastroenteritis, septicemia \\
D/Gallinarum & Poultry & Gastroenteritis, septicemia \\
B/Abortusovis & Sheep & Septicemia, abortion \\
B/Abortusequi & Horses & Septicemia, abortion \\
C/Choleraesuis & Swine & Septicemia, fever \\
\hline
\end{tabular}


wild animals in the farm [52,130]. Flies act as mechanical vectors aiding transmission of the bacteria from one farm to another and transmission from cattle to humans has also been documented [135]. Animals in the farm become infected through ingesting Salmonellainfected flies. Salmonella has been isolated from flies around poultry farms and environments [136-138]. Wild animals such as wild birds and other wildlife are regarded as important reservoirs of Salmonella infection $[46,47,49,51,52]$. They are responsible for the introduction and dissemination of the bacteria into livestock farms through contamination of feed, water or direct environmental contamination [130]. Human trafficking in the farm has been shown to increase the risk of Salmonella infection in pigs, chickens, and hens [130]. Another study [139] reported a positive correlation between the entrance of visitors and Salmonella prevalence on the farm. Findings from the study suggested that, an entrance of visitors in the farms was associated with higher Salmonella prevalence.

\section{Overview of AMR in Foodborne Pathogens}

Antibiotics or antimicrobial agents were discovered around the middle of the $19^{\text {th }}$ century and since then, they have been used for combating the threat posed by pathogenic bacterial agents in both human and animal medicine [140,141]. They are natural, synthetic or semi-synthetic products that are used to inhibit the growth of microorganisms (bacteria) on one end and in the chemotherapy and prevention of infectious diseases in both animals and humans on the other end [142]. Furthermore, farmers use antibiotics extensively either as feed additives or growth promoters to enhance the growth of food animals [143]. Unfortunately, the extensive use or misuse of the antimicrobial agents not only in the treatment of human and animal infections but also as growth promoting agents in livestock production has led to the evolutionary emergence of resistance to one or more of the antimicrobial agents used against the bacterial agents [143,144-148].

AMR is the ability of the microorganisms specifically bacteria to inhibit the agents through different mechanisms from working against them. Over the years, AMR has caused serious public health threat; as the antibiotic agents are no longer effective against the bacterial agents and hence, leading to treatment failures, high mortalities and increase the length of hospitalization among others [145]. Specific bacteria could be resistant to one or more groups of antimicrobial agents. Recently, the European Union (EU) in an effort to reduce the prevalence of antimicrobial-resistant bacteria introduced several actions; one of which is the removal of antimicrobial agents use as growth promoters from all the livestock industry [149]. Furthermore, all countries in the EU have initiated and adopted a new legislation program for surveillance and monitoring of AMR of selected zoonotic and animal pathogens [149].
Among the major contributing factor to the magnitude of the global challenge of AMR is the extensive utilization of antibiotics in food animals [144]. Antibiotics have been used frequently in intensive farming management of food animals such as poultry, pigs and fish for therapeutic or prophylactic purposes for treatment or prevention of bacterial diseases. Furthermore, antibiotics have been extensively used by farmers as growth promoters for enhancing the rapid growth of food animals including poultry and fishes. This further exacerbates the emergence and spread of AMR including MDR [144,150]. The AMR bacteria and antibiotic-resistant genes can cause human infections through entry and transmission at any stage of the food production cycle $[144,151,152]$. Thus, emergence of AMR bacterial strains along the food chain has posed serious global public health concern because several studies have reported the infection, colonization and contamination of food animals and their products by one or more of the resistant strains such as AMR Campylobacter spp., methicillin-resistant Staphylococcus aureus (MRSA) and extended-spectrum beta-lactamase Enterobacteriaceae family such as E. coli, Salmonella spp., and Shigella spp. [153-155].

The recent emergence of AMR bacteria such as carbapenem-resistant Enterobacteriaceae, colistin-resistant $E$. coli and emerging livestock associated-MRSA has further worsened the current AMR global challenge $[154,156]$. All these resistant strains have food animals serving as reservoirs and have been associated with high genetic exchanges, virulence mechanisms and adaptability to multiple hosts $[153,154,156,157]$. These factors can lead to the rapid emergence of novel pathogens that are more resistant, virulent and mobile strains often termed as "superbugs." The resistant bacterial strains can affect humans through two ways; either following direct contact with infected/or colonized animals or a biological substance such as feces, urine, saliva, or blood of these animals and the other is indirectly along the food chain through consumption of contaminated food or food derived products [151].

\section{Antimicrobial Resistance (MDR) of Salmonella and Its Surveillance}

The first incidence of antibiotic resistance of Salmonella was reported in the early 1960s; this was resistance to a single antibiotic namely chloramphenicol [158]. Since then, the isolation frequency of Salmonella serotypes resistant to one or more antibiotics has increased globally [159]. This has been related to the misuse, overuse and easy accessibility of antimicrobials in many countries. In the United States, it has been estimated that Salmonella causes an estimated 100,000 antimicrobial-resistant infections annually [33]. The overall pattern and trend as well as frequencies of resistance can vary remarkably from one country to another [160]. The U.S's FDA 
has recognized the occurrence of AMR in Salmonella as well as other bacterial species as a global public health threat since 2003 [15]. Multidrug resistance in Salmonella is defined as resistance toward the traditional first-line antibiotics such as ampicillin, chloramphenicol and trimethoprim-sulfamethoxazole [57]. This is a major threat to the public health because a majority of the MDR Salmonella infections in humans are acquired by ingestion of contaminated foods of animal origin such as swine, chicken and chicken products such as eggs.

Although the occurrence of NTS in food animals and their susceptibilities to commonly used antimicrobials is poorly understood in developing countries [9], few studies in recent years were conducted to provide epidemiological insights into the ecology, dynamics, environmental drivers and persistence of resistance genes as well as its subsequent transmission along the food chain. For instance, a recent review demonstrated that the prevalence of MDR Salmonella is on the rise in the African continent and this may pose difficulty in the treatment of human salmonellosis [54]. In Nigeria, MDR Salmonella was reported in Japanese quails suggesting public health risks from direct consumption of these birds or contact with carriers quail birds [20]. Similarly, in Ugandan layer hen farms $(n=237)$, MDR Salmonella was identified in $12(15.4 \%)$ of the total isolates recovered and the highest resistance was against ciprofloxacin followed by sulfonamides and sulfamethoxazole/trimethoprim [9]. In Brazil, a 20-year meta-analysis study (1995-2014) was conducted to assess the profile and temporal patterns of AMR of NTS sourced from humans and poultry-related samples [30]. The highest level of resistance was demonstrated against sulfonamides, nalidixic acid and tetracycline by the NTS isolates of poultry origin. Similarly, those of human origins had resistance toward sulfonamides, tetracycline and ampicillin [30]. One study from Taiwan and Thailand [161] isolated and identified Salmonella Choleraesuis strains that demonstrated resistance toward cephalosporins and fluoroquinolones. Similarly, another study [148] isolated Salmonella from chicken eggs sourced from different marketing channels and poultry farms in Northern India. Moreover, findings from the study revealed that the isolates demonstrated resistance toward bacitracin, colistin, and polymyxin-B. Salmonella displaying MDR towards ampicillin and tetracycline was also isolated from table poultry eggs sampled from different sources in Izatnagar, India [162].

Several clones of MDR Salmonella have emerged during the late 1990s and early 2000s and since then, their prevalences have expanded globally [15]. Recently, the increasing prevalence of MDR Salmonella as well as resistance towards clinically important antimicrobials such as fluoroquinolones and third-generation cephalosporins has become an emerging problem worldwide [26-29]. A recent study from Egypt [163] highlighted the increasing incidence of MDR S. enterica in meat and dairy products, which are probably transferred to humans along the food chain subsequently leading to therapeutic failures. In another similar study by Rotimi et al. [164] conducted in Kuwait and the United Arab Emirates, the increasing trend of MDR among Salmonella isolates was further demonstrated and the rate of resistance toward the third-generation cephalosporins such as ceftriaxone and cefotaxime was reported to have increased by five-fold. Another study from Gondar town of Ethiopia assessed the AMR pattern of Salmonella isolates recovered from different sources in the butcher shops [165]. About $28.3 \%(n=15)$ of the isolates were MDR with the highest isolation from the meat samples. Ceftriaxone resistance in Salmonella remains a serious public health threat because it is commonly used to treat severe Salmonella infections especially in children [18]. In an effort to characterize ceftriaxone-resistant Salmonella infections in humans from the United States, data reported from the National Antimicrobial Resistance Monitoring System (NARMS) during 1996-2013 were utilized [18]. From this analysis, it was found that $978(2.9 \%)$ of the total 34,100 NTS isolates sourced from humans were ceftriaxone-resistant and many of these (about 40\%) were from children younger than 18 years. To identify the diversity of AMR phenotypes among Salmonella isolates recovered from integrated commercial broiler farms, retrospective data from the United States NARMS reports were analysed [17]. According to this analysis, 25 AMR phenotypes were observed in the Salmonella isolates recovered from two broiler chicken farms with the isolates displaying resistance toward streptomycin alone or in combination with other antibiotics was the most prevalent AMR phenotypes (36.3\%) [17]. Another study from chicken carcasses in Myanmar revealed that $72(52.2 \%)$ of the Salmonella isolates derived from chicken meat sold at retail markets were MDR [166]. Similarly, a majority $(93.75 \%)$ of the Salmonella isolates recovered from retail chicken and pork in China displayed resistance to multiple antibiotics [157]. In the same study, it was found that MDR was linked only to the Salmonella isolates from chickens, whereas those from pork were only resistant to tetracycline. About $7 \%$ of the Salmonella isolates derived from different sources of poultry farms in the Southeastern United States exhibited resistance to at least one antimicrobials tested [7]. High AMR was observed towards tetracycline, streptomycin and nalidixic acid. Furthermore, a single isolate of $S$. Mbandaka exhibited MDR towards tetracycline, amoxicillin/clavulanic acid and ampicillin [7].

The NARMS was formed two decades ago and it entails an integrated one-health approach in the surveillance and monitoring of AMR in foodborne enteric bacteria from humans, retail meats and food animals [167]. Its primary objectives are to timely identify AMR and provide an updated data on the temporal patterns of antibiotic susceptibilities in Salmonella and 
some selected foodborne enteric bacteria from human and animal populations as well as retail meats. It is the colaboration between the CDC, The U.S. FDA's center for veterinary medicine and the USDA [167]. In 2007 , the NARMS provided an executive summary of the resistance trends among the NTS isolates and the report indicated that $53.9 \%, 72 \%$, and $43.1 \%$ of the isolates respectively from chickens, cattle, and swine exhibited resistance toward at least one antimicrobial tested [168]. In a similar report, NARMS also reported that the most common MDR phenotype among the Salmonella isolates was to five antimicrobials namely ampicillin, chloramphenicol, streptomycin, sulfamethoxazole, and tetracyclines (ACSSuT) and this was detected from $1.5 \%, 4.8 \%, 16.2 \%$, and $10.9 \%$ of the isolates recovered from chickens, turkeys, cattle, and swine respectively [168]. The antibiotic drugs amoxicillin/clavulanic acid, ampicillin, ceftiofur, cefoxitin, chloramphenicol, streptomycin, sulfonamides, and tetracyclines had the highest percentage of resistant Salmonella isolates and percentage of the resistant isolates to these drugs has increased since 1997 [168].

In 2013, according to the NARMS's report data for the U.S., AMR among Salmonella strains varied by serotypes [169]. This report highlighted that 3\% $(61 / 2178)$ of the NTS isolates were resistant to nalidixic acid and the common serotypes among the 55 ceftriaxone-resistant isolates were SN, $S$. Dublin, ST, SH and $S$. Infantis. Among these serotypes, Newport, Typhimurium and Heidelberg have been reported to be associated with human infections from food of animal origins $[170,171]$. Hence, this presented an increasing threat to public health. In another study [172], it was reported that the AMR patterns of over $80 \%$ of Salmonella strains from both human's and animal's sources tested against antimicrobials revealed similar resistance patterns and that the frequently encountered resistance phenotype was resistance to ampicillin, sulfonamides, streptomycin, chloramphenicol and tetracycline (ASSCT). This resistance phenotype was found in $73 \%$ and $76 \%$ of strains sourced from animal and humans respectively [172]. An earlier study [173] conducted in the Netherlands between 1972 and 1974 screened about 50,000 Salmonella isolates recovered from different sources (humans, animals, animal products, sewages, etc.) for resistance against ampicillin, chloramphenicol, kanamycin and tetracyclines. The results of this study indicated that the incidence of resistance to at least one of these antimicrobials tested ranged from $39.2 \%$ to $45.6 \%$ [173].

There is an increasing frequency of the occurrence of MDR serotypes especially Typhimurium and Newport; and these serotypes along with Heidelberg and Enteritidis have been identified to be associated with human infections from foods of animal origin [170,171]. Recently, surveillance report from the NARMS has shown an increased frequency of the occurrence of extended-spectrum cephalosporin resistance of the serotype Heidelberg isolated from food animals at slaughter, retail meat and humans [174]. In 1984, the ST Definitive Type 104 was first identified in the UK [175] and later isolated from other parts of the world. The emergence of this phage type presented a major threat to public health because it exhibits resistance to five antimicrobials ACSSuT [176,177]. Compared with infections caused by other susceptible strains, MDR S. enterica serotype Typhimurium has been associated with high risk of invasive infection, long duration of hospitalization, longer illness and increased risk of death [15]. For instance, a very unique characteristic of ST serotype is that its genomic element can carry resistance to five antimicrobials namely ampicillin, chloramphenicol, streptomycin, sulfonamides and tetracyclines, which can either spread horizontally to other serotypes or acquire additional resistance determinants from other serotypes [15]. Mobile DNA elements such as integrons and plasmids play an important role in the transmission and dissemination of AMR determinants among Salmonella strains [178]. These elements (integrons and plasmids) carry the genes conferring AMR in Salmonella and they could be transmitted through process refer to as conjugation [178].

\section{Public Health Significance of Salmonella}

Recently, technological advancements in traveling, globalization and also growth in international trade between many countries in the world have led to the rapid dissemination of foodborne pathogens, contaminants in foodstuffs and other pathogens of potential threat to the human race. Consequently, this lead to an increased perception of the need for adoption of surveillance systems to ensure food safety - identification of foods involved in foodborne outbreaks - due to its economic importance; because the identification of only one contaminated food product may lead to discarding of tonnes of foods resulting in economic losses to the production sector and international trade restrictions [179]. Salmonellosis is one of the most frequently reported foodborne disease outbreaks worldwide but mainly common in developing countries such as India, Asia and Africa $[23,54,180]$. Salmonellosis poses public health threats due to its high endemicity, difficulty in adopting control measures, and because of its significant morbidity and mortality rates. According to the WHO, Salmonella is among pathogens that caused the greatest impact on the human population, and has been associated with outbreaks and sporadic cases of human foodborne diseases worldwide. Poultry and poultry products such as eggs have been frequently reported to be associated with salmonellosis outbreaks and therefore, are generally recognized as primary sources of the disease [181]. Typically, humans become infected through ingestion of foods contaminated with animal feces or cross-contaminated by other sources.

Enteric fever, which is caused by the typhoidal strains $S$. Typhi and $S$. Paratyphi, has been reported 
endemic in the Southeast and Central Asia, where it causes 200,000 deaths and 22 million illnesses per year [182]. Serovars of NTS are widespread and are commonly associated with specific animals. In the human hosts, they typically cause a self - limiting gastroenteritis with symptoms such as fever, diarrhea, vomiting, and stomach cramps [183]. These symptoms could be accompanied by prolonged fecal shedding of the bacteria for more than a month. Globally, gastroenteritis, the most common form of NTS infection, accounts for about 93.8 million cases and 155,000 deaths per year [34]. Based on a surveillance data for 2001-2005, the frequently isolated serovar responsible for NTS infection worldwide was SE $(65 \%)$, followed by ST and SN, which respectively accounted for $12 \%$ and $4 \%$ of the clinical isolates recovered [184]. Similarly, in Asia, Latin America and Europe, SE was the common serotype identified accounting for $38 \%$, $31 \%$, and $87 \%$ of the clinical isolates respectively. Whereas, in Africa, both SE and ST were reportedly identified as the common serotypes occurring in $26 \%$ and $25 \%$ of the recovered clinical isolates [184]. In 2010 alone, the annual costs associated with salmonellosis were estimated at US $\$ 2.71$ billion for 1.4 million cases [185]. Similarly, in the US, the estimated costs of medical expenses, sick leaves and loss of productivity related to the high incidence of salmonellosis ranged from US\$1.3 to US $\$ 4.0$ billion a year [186].

\section{Conclusion}

The NTS especially serovars Typhimurium, Enteritidis, Heidelberg and Newport have been reported in many outbreaks of human salmonellosis around the globe and these outbreaks have been linked with consumption of Salmonella-contaminated foods of animal origins such as poultry and related derived products, pork, fish etc. NTS like many other enteropathogenic bacteria has evolved in utilizing a variety of virulence markers and other cellular machinery to colonize the host by attaching, invading and bypassing the host's gastrointestinal defense mechanisms. These factors included flagella, capsule, plasmids, adhesion systems and T3SS encoded on the SPI- 1 and SPI- 2 and other SPIs. These mechanisms are essential for and play crucial roles in the pathogenesis of Salmonella infections. Furthermore, the NTS strains have been demonstrated to possess MDR toward the first-line and second-line antimicrobial drugs worldwide. Consequently, an increased frequency of hospitalization, treatment failures, treatment costs, increased morbidity and mortality rates from foodborne salmonellosis cases have been reported worlwide.

\section{Author's Contributions}

SMJ conceived the review project, design of the review, literature search, wrote the first manuscript draft and edited the final manuscript. All sections of the final review were carefully read, reviewed and approved by the author.

\section{Acknowledgments}

The author is thankful to Faculty of Veterinary Medicine, University of Maiduguri, Nigeria for providing necessary facilities for this review.

\section{Competing Interests}

The author declares that he has no competing interests.

\section{Publisher's Note}

Veterinary World remains neutral with regard to jurisdictional claims in published institutional affiliation.

\section{References}

1. Lee, K.M., Runyon, M., Herrmanm, T.J., Phillips, R. and Hsieh, J. (2015) Review of Salmonella detection and identification methods: Aspects of rapid emergency response and food safety. Food Control, 47(2015): 264-276.

2. Newell, D.G., Koopmans, M., Verhoef, L., Duizer, E., Aidara-Kane, A., Sprong, H., Opsteegh, M., Langelaar, M., Threfall, J., Scheutz, F., van der Giessen, J. and Kruse, H. (2010) Food-borne diseases the challenges of 20 years ago still persist while new ones continue to emerge. Int. J. Food Microbiol., 139(1): S3-S15.

3. Putturu, R., Eevuri, T., Ch, B. and Nelapati, K. (2015) Salmonella enteritidis-foodborne pathogen-a review. Int. J. Pharm Biol. Sci., 5(1): 86-95.

4. Alzwghaibi, A.B., Yahyaraeyat, R., Fasaei, B.N., Langeroudi, A.G. and Salehi, T.Z. (2018) Rapid molecular identification and differentiation of common Salmonella serovars isolated from poultry, domestic animals and foodstuff using multiplex PCR assay. Arch. Microbiol., 200(7): 1009-1016.

5. Eguale, T. (2018) Non-typhoidal Salmonella serovars in poultry farms in central Ethiopia: Prevalence and antimicrobial resistance BMC Vet. Res., 14(1): 217.

6. Zishiri, O.T., Mkhize, N. and Mukaratirwa, S. (2016) Prevalence of virulence and antimicrobial resistance genes in Salmonella spp. isolated from commercial chickens and human clinical isolates from South Africa and Brazil. Onderstepoort J. Vet. Res., 83(1): e1-e11

7. Velasquez, C.G., MacKlin, K.S., Kumar, S., Bailey, M., Ebner, P.E., Oliver, H.F., Martin-Gonzalez, F.S. and Singh, M. (2018) Prevalence and antimicrobial resistance patterns of Salmonella isolated from poultry farms in Southeastern United States. Poult. Sci., 97(6): 2144-2152.

8. Ed-dra, A., Filali, F.R., Karraouan, B., El Allaoui, A., Aboulkacem, A. and Bouchrif, B. (2017) Prevalence, molecular and antimicrobial resistance of Salmonella isolated from sausages in Meknes, Morocco. Microb. Pathog., 105: 340-345.

9. Odoch, T., Wasteson, Y., L'Abée-Lund, T., Muwonge, A., Kankya, C., Nyakarahuka, L., Tegule, S. and Skjerve, E. (2017) Prevalence, antimicrobial susceptibility and risk factors associated with non-typhoidal Salmonella on Ugandan layer hen farms. BMC Vet. Res., 13(1): 365.

10. Mezal, E.H., Sabol, A., Khan, M.A., Ali, N., Stefanova, R. and Khan, A.A. (2014) Isolation and molecular characterization of Salmonella enterica serovar Enteritidis from poultry house and clinical samples during 2010. Food Microbiol., 38: 67-74.

11. Xiong, D., Song, L., Pan, Z. and Jiao, X. (2018) Identification and discrimination of Salmonella enterica serovar Gallinarum biovars Pullorum and Gallinarum based on a one-step multiplex PCR assay. Front. Microbiol., 9: 1718.

12. Penha Filho, R.A.C., Ferreira, J.C., Kanashiro, A.M.I., Darini, A.L.C. and Berchieri, J.A. (2016) Antimicrobial 
susceptibility of Salmonella gallinarum and Salmonella Pullorum isolated from ill poultry in Brazil. Ciência Rural, 46(3): 513-518.

13. Eriksson, H., Söderlund, R., Ernholm, L., Melin, L. and Jansson, D.S. (2018) Diagnostics, epidemiological observations and genomic subtyping in an outbreak of pullorum disease in non-commercial chickens. Vet. Microbiol., 217: 47-52.

14. Yue, M. and Schifferli, D.M. (2013) Allelic variation in Salmonella: An underappreciated driver of adaptation and virulence. Front. Microbiol., 4: 419.

15. Niki, M., Shakeel, A., Zahid, K. and Konstantinos, C.K (2017) Prevalence, Risks and Antibiotic Resistance of Salmonella in Poultry Production Chain. In: Current Topics in Salmonella and Salmonellosis. InTechOpen, London, United Kingdom p216-234.

16. Elkenany, R.M., Eladl, A.H. and El-Shafei, R.A. (2018) Genetic characterization of class 1 integrons among multidrug-resistant Salmonella serotypes in broiler chicken farms. J. Glob. Antimicrob. Resist., 14: 202-208.

17. Liljebjelke, K.A., Hofacre, C.L., White, D.G., Ayers, S., Lee, M.D. and Maurer, J.J. (2017) Diversity of antimicrobial resistance phenotypes in Salmonella isolated from commercial poultry farms. Front. Vet. Sci., 4: 96.

18. Iwamoto, M., Reynolds, J., Karp, B.E., Tate, H., FedorkaCray, P.J., Plumblee, J.R., Hoekstra, R.M., Whichard, J.M. and Mahon, B.E. (2017) Ceftriaxone-resistant nontyphoidal Salmonella from humans, retail meats, and food animals in the United States, 1996-2013. Foodborne Pathog. Dis., 14(2): 74-83.

19. Faruq, A.A., Hassan, M.M., Uddin, M.M., Rahman, M.L., Rakib, T.M., Alam, M. and Islam, A. (2016) Prevalence and multidrug resistance pattern of Salmonella isolated from resident wild birds of Bangladesh. Int. J. One Health, 2: $35-41$.

20. Omoshaba, E.O., Olufemi, F.O., Ojo, O.E., Sonibare, A.O. and Agbaje, M. (2017) Multidrug-resistant Salmonellae isolated in Japanese quails reared in Abeokuta, Nigeria. Trop. Anim. Health Prod., 49(7): 1455-1460.

21. Migura-Garcia, L., Ramos, R. and Cerdà-Cuéllar, M. (2017) Antimicrobial resistance of Salmonella serovars and Campylobacter spp. Isolated from an opportunistic gull species, yellow-legged gull (Larus michahellis). J. Wildl. Dis., 53(1): 148-152.

22. Anjum, M.F., Duggett, N.A., AbuOun, M., Randall, L., Nunez-Garcia, J., Ellis, R.J., Rogers, J., Horton, R., Brena, C., Williamson, S., Martelli, F., Davies, R. and Teale, C. (2016) Colistin resistance in Salmonella and Escherichia coli isolates from a pig farm in Great Britain. J. Antimicrob. Chemother., 71(8): 2306-2313.

23. Phoon, Y.W., Chan, Y.Y.C. and Koh, T.H. (2015) Isolation of multidrug-resistant Salmonella in Singapore. Singapore Med. J., 56(8): 142-144.

24. Andoh, L.A., Ahmed, S., Olsen, J.E., Obiri-Danso, K., Newman, M.J., Opintan, J.A., Barco, L. and Dalsgaard, A. (2017) Prevalence and characterization of Salmonella among humans in Ghana. Trop. Med. Health, 45: 3.

25. Afema, J.A., Mather, A.E. and Sischo, W.M. (2015) Antimicrobial resistance profiles diversity in Salmonella from humans cattle, 2004-2011. Zoonoses Public Health, 62(7): 506-517.

26. Brands, D.A., Inman, A.E., Gerba, C.P., Maré, C.J., Billington, S.J., Saif, L.A., Levine, J.F. and Joens, L.A. (2005) Prevalence of Salmonella spp. In oysters in the United States. Appl. Environ. Microbiol., 71(2): 893-897.

27. Chao, G., Zhou, X., Jiao, X., Qian, X. and Xu, L. (2007) Prevalence and antimicrobial resistance of foodborne pathogens isolated from food products in China. Foodborne Pathog. Dis., 4(3): 277-284.

28. Gebreyes, W.A. and Thakur, S. (2005) Multidrug-resistant Salmonella enterica serovar Muenchen from pigs and humans and potential interserovar transfer of antimicrobial resistance. Antimicrob. Agents Chemother., 49(2): 503-511.

29. Glenn, L.M., Lindsey, R.L., Folster, J.P., Pecic, G., Boerlin, P., Gilmour, M.W., Harbottle, H., Zhao, S., McDermott, P.F. and Fedorka-Cray, P.J. (2013) Antimicrobial resistance genes in multidrug-resistant Salmonella enterica isolated from animals, retail meats, and humans in the United States and Canada. Microb. Drug Resist., 19(3): 175-184.

30. Voss-Rech, D., Potter, L., Vaz, C.S.L., Pereira, D.I.B., Sangioni, L.A., Vargas, A.C. and de Avila, B.S. (2017) Antimicrobial resistance in nontyphoidal Salmonella isolated from human and poultry-related samples in Brazil: 20-year meta-analysis. Foodborne Pathog. Dis., 14(2): 116-124.

31. Michael, G.B. and Schwarz, S. (2016) Antimicrobial resistance in zoonotic nontyphoidal Salmonella: An alarming trend? Clin. Microbiol. Infect., 22(12): 968-974

32. Shrestha, K.L., Pant, N.D., Bhandari, R., Khatri, S., Shrestha, B. and Lekhak, B. (2016) Re-emergence of the susceptibility of the Salmonella spp. Isolated from blood samples to conventional first-line antibiotics. Antimicrob. Resist. Infect. Control., 5(2016): 22.

33. Angelo, K.M., Reynolds, J., Karp, B.E., Hoekstra, R.M., Scheel, C.M. and Friedman C. (2016) Antimicrobial resistance among nontyphoidal Salmonella isolated from blood in the United States, 2003-2013. J. Infect. Dis., 214(10): 1565-1570.

34. Majowicz, S.E., Musto, J., Scallan, E., Angulo, F.J., Kirk, M., O'Brien, S.J., Jones, T.F., Fazil, A. and Hoekstra, R.M (2010) The global burden of nontyphoidal Salmonella gastroenteritis. Clin. Infect. Dis., 50(6): 882-889.

35. Prestinaci, F., Pezzotti, P. and Pantosti, A. (2015) Antimicrobial resistance: A global multifaceted phenomenon. Pathog. Glob. Health, 109(7): 309-318.

36. Li, B., Liu, C., Liu, L., Li, S., Fan, N., Hou, H., Jin, J. and Xing, Y. (2018) Prevalence and etiologic agent of Salmonella in livestock and poultry meats in Huai'an City during 2015-2016. Wei Sheng Yan Jiu, 47(2): 260-300.

37. Adhikari, S.K., Gyawali, A., Shrestha, S., Shrestha, S.P., Prajapati, M. and Raj, D. (2018) Molecular confirmation of Salmonella Typhimurium in poultry from Kathmandu valley. J. Nepal Agric. Res. Counc., 4(1): 86-89.

38. Shah, D.H., Paul, N.C., Sischo, W.C., Crespo, R. and Guard, J (2017) Microbiology and food safety: Population dynamics and antimicrobial resistance of the most prevalent poultry-associated Salmonella serotypes. Poult. Sci., 96(3): 687-702.

39. Tarabees, R., Elsayed, M.S.A., Shawish, R., Basiouni, S. and Shehata, A.A. (2017) Isolation and characterization of Salmonella Enteritidis and Salmonella Typhimurium from chicken meat in Egypt. J. Infect. Dev. Ctries., 11(4): 314-319.

40. Fagbamila, I.O., Barco, L., Mancin, M, Abdu, P.A., Kabir, J., Umoh, J., Ricci, A. and Muhammad, M. (2017) Salmonella serovars and their distribution in Nigerian commercial chicken layer farms. PLoS One, 12(3): e0173097.

41. Krawiec, M., Kuczkowski, M., Kruszewicz, A.G. and Wieliczko, A. (2015) Prevalence and genetic characteristics of Salmonella in free-living birds in Poland. BMC Vet. Res., 11: 15 .

42. Myšková, P. and Íšková, R.K. (2017) Prevalence and characteristics of Salmonella in retail poultry and pork meat in the Czech Republic in 2013-2014. Czech J. Food Sci., 35(2): 106-112.

43. Rönnqvist, M., Välttilä, V., Ranta, J. and Tuominen, P. (2018) Salmonella risk to consumers via pork is related to the Salmonella prevalence in pig feed. Food Microbiol., 71(2018): 93-97.

44. Cummings, K.J., Rodriguez-Rivera, L.D., Grigar, M.K., Rankin, S.C., Mesenbrink, B.T., Leland, B.R. and Bodenchuk, M.J. (2016) Prevalence and characterization of Salmonella isolated from feral pigs throughout Texas. Zoonoses Public Health, 63(6): 436-441. 
45. Afema, J.A. and Sischo, W.M. (2016) Salmonella in wild birds utilizing protected and human-impacted habitats, Uganda. Ecohealth, 13(3): 558-569.

46. Mustaffa, S.S., Saleha, A.A. and Jalila, A. (2014) Occurrence of antibiotic-resistant Salmonella and Campylobacter in wild birds. J. Vet. Malaysia, 26(2): 17-19.

47. Botti, V., Valérie, N.F., Domenis, L., Orusa, R., Pepe, E., Robetto, S. and Guidetti, C (2013) Salmonella spp. And antibiotic-resistant strains in wild mammals and birds in North-Western Italy from 2002 to 2010. Vet. Ital., 49(2): 195-202.

48. Grigar, M.K., Cummings, K.J., Rodriguez-Rivera, L.D., Rankin, S.C., Johns, K., Hamer, G.L. and Hamer, S.A. (2016) Salmonella surveillance among great-tailed grackles (Quiscalus mexicanus) and other urban bird species in eastern Texas. Vector-Borne Zoonotic Dis., 16(12): 752-757.

49. Lawson, B., De Pinna, E., Horton, R.A, Macgregor, S.K., John, S.K., Chantrey, J., Duff, J.P. and Kirkwood, J.K. (2014) Epidemiological evidence that garden birds are a source of human salmonellosis in England and Wales. PLoS One, 9(2): e88968.

50. Matias, C.A.R., Pereira, I.A., Reis, E.M.F., Rodrigues, D.P. and Siciliano, S. (2016) Frequency of zoonotic bacteria among illegally traded wild birds in Rio de Janeiro. Braz. J Microbiol., 47(4): 882-888.

51. Brobey, B., Kucknoor, A. and Armacost, J. (2017) Prevalence of Trichomonas, Salmonella, and Listeria in wild birds from Southeast Texas. Avian Dis., 61(3): 347-352.

52. Andrés-Barranco, S., Vico, J.P., Garrido, V., Samper, S., Herrera-León, S., de Frutos C. and Mainar-Jaime, R.C. (2014) Role of wild bird and rodents in the epidemiology of subclinical salmonellosis in finishing pigs. Foodborne Pathog. Dis., 11(9): 689-697.

53. Dang-Xuan, S., Nguyen-Viet, H., Pham-Duc, P., Unger, F., Tran-Thi, N., Grace, D. and Makita, K. (2019) Risk factors associated with Salmonella spp. prevalence along smallholder pig value chains in Vietnam. Int. J. Food Microbiol., 290(1): 105-115.

54. Smith, S.I., Seriki, A. and Ajayi, A. (2016) Typhoidal and non-typhoidal Salmonella infections in Africa. Eur. J. Clin. Microbiol. Infect. Dis., 35(112): 1913-1922.

55. Le Minor, L. (1991) The genus Salmonella. In: Balows, A., Truper, H.G., Dworkin, C., Harder, W. and Scheilfer, K.H., editors. The Prokaryotes. Springer-Varlag, New York. p2760-2774.

56. D'Aoust, J.Y. (1989) Salmonella. In: Doyle, M.P., editor. Foodborne Bacterial Pathogens. Marcel Inc., New York. p327-445.

57. Eng, S.K., Pusparajah, P., Ab Mutalib, N.S., Ser, H.L., Chan, K.G. and Lee, L.H. (2015) Salmonella: A review on pathogenesis, epidemiology and antibiotic resistance. Front. Life Sci., 8(3): 284-293.

58. Popoff, M.Y., Bockemühl, J. and Gheesling, L.L. (2003) Supplement 2001 (no. 45) to the Kauffmann-White scheme. Res. Microbiol., 154(3): 173-174.

59. Reeves, M.W., Evins, G.M., Heiba, A.A., Plikaytis, B.D. and Farmer, J.J. (1989) Clonal nature of Salmonella Typhi and its genetic relatedness to other salmonellae as shown by multilocus enzyme electrophoresis and proposal of Salmonella bongori Comb. J. Clin. Microbiol., 27(2): 313-320.

60. Brenner, F.W., Villar, R.G., Angulo, F.J., Tauxe, R. and Swaminathan, B. (2000) Salmonella nomenclature. J. Clin. Microbiol., 38(7): 2465-2467.

61. Kauffmann, F. (1941) A typical variant and a new serological variation in the Salmonella group. J. Bacteriol., 41(2): 127-141.

62. White, P.B. (1925) Med. Res. Council, Gt. Brit. Spec. Rep. Ser. no. 91.

63. McQuiston, J.R., Fields, P.I., Tauxe, R.V. and Logsdon, J.M. (2008) Do Salmonella carry spare tyres? Trends Microbiol., 16(4): 142-148.
64. Guibourdenche, M., Roggentin, P., Mikoleit, M., Fields, P.I., Bockemühl, J., Grimont, P.A.D. and Weill, F.X. (2010) Supplement 2003-2007 (No. 47) to the WhiteKauffmann-Le Minor scheme. Res. Microbiol., 161(1): 26-29.

65. Popoff, M.Y. and Le Minor, L. (2005) Salmonella. In: Brenner, D.J., Kreig, N.R. and Staley, J.T., editors. Bergey's Manual of Systematic Bacteriology. $2^{\text {nd }}$ ed. Springer, New York, USA. p764-799.

66. Rambach, A. (1990) New plate medium for facilitated differentiation of Salmonella spp. From Proteus spp. And other enteric bacteria. Appl. Environ. Microbiol., 56(1): 301-303.

67. Andrews, W.H. and Hammack, T.S. (2001) Salmonella. Bacteriological Analytical Manual. Ch. 5. U.S. Food and Drug Administration, United States.

68. Anderson, R.C. and Ziprin, R.L. (2001) Bacteriology of Salmonella. In: Hui, Y.H., Pierson, M.D. and Gorham, J.R., editors. Foodborne Disease Handbook, Bacterial Pathogens. Marcel Dekker, New York. p247-263.

69. ISO. (2002). Microbiology of Food and Animal Feeding Stuffs. Horizontal Method for the Detection of Salmonella spp. ISO No. 6579, Geneva, Switzerland.

70. Pui, C.F., Wong, W.C., Chai, L.C., Tunung, R., Jeyaletchumi, P., Noor, H.M.N., Ubong, A., Farinazleen, M.G., Cheah, Y.K. and Son, R. (2011) Salmonella: A foodborne pathogen. Int. Food Res. J., 18(1): 465-473.

71. Gerlach, R.G. and Hensel, M. (2007) Salmonella pathogenicity islands in host specificity, host pathogen-interactions and antibiotics resistance of Salmonella enterica. Berl. Munch. Tierarztl. Wochenschr., 120(7-8): 317-327.

72. Daigle, F. (2008) Typhi genes expressed during infection or involved in pathogenesis. J. Infect. Dev. Ctries., 2(6): 431-437.

73. Sabbagh, S.C., Forest, C.G., Lepage, C., Leclerc, J.M. and Daigle, F. (2010) So similar, yet so different: Uncovering distinctive features in the genomes of Salmonella enterica serovars Typhimurium and Typhi. FEMS Microbiol. Lett., 305(1): 1-13.

74. Lee, M.D., Curtiss, R. and Peay, T. (1996) The effect of bacterial surface structures on the pathogenesis of Salmonella Typhimurium infection in chickens. Avian Dis., 40(1): 28-36.

75. Foley, S.L., Lynne, A.M. and Nayak, R. (2008) Salmonella challenges: Prevalence in swine and poultry and potential pathogenicity of such isolates. J. Anim. Sci., 86(14): E149-E162.

76. Kaur, J. and Jain, S.K. (2012) Role of antigens and virulence factors of Salmonella enterica serovar Typhi in its pathogenesis. Microbiol. Res., 167(4): 199-210.

77. Schmidt, H. and Hensel, M. (2004) Pathogenicity Islands in bacterial pathogenesis. Clin. Microbiol. Rev., 17(1): 14-56.

78. Marcus, S.L., Brumell, J.H., Pfeifer, C.G. and Finlay, B.B. (2000) Salmonella pathogenicity islands: Big virulence in small packages. Microbes Infect., 2(2): 145-156.

79. Foley, S.L. and Lynne, A.M. (2008) Food animal-associated Salmonella challenges: Pathogenicity and antimicrobial resistance. J. Anim. Sci., 86(1): E173-E187.

80. Van Asten, A.J.A. and Van Dijk, J.E. (2005) Distribution of "classic" virulence factors among Salmonella spp. FEMS Immunol. Med. Microbiol., 44(3): 251-259.

81. Stevens, M.P., Humphrey, T.J. and Maskell, D.J. (2009) Molecular insights into farm animal and zoonotic Salmonella infections. Philos. Trans. R. Soc. B. Biol. Sci., 364(1530): 2709-2723.

82. Leung, K.Y., Siame, B.A., Snowball, H. and Mok, Y.K. (2011) Type VI secretion regulation: Crosstalk and intracellular communication. Curr. Opin. Microbiol., 14(1): 9-15.

83. Bingle, L.E., Bailey, C.M. and Pallen, M.J. (2008) Type VI secretion: A beginner's guide. Curr. Opin. Microbiol., 11(1): 3-8.

84. Amavisit, P., Lightfoot, D., Browning, G.F. and 
Markham, P.F. (2003) Variation between pathogenic serovars within Salmonella pathogenicity islands. J. Bacteriol., 185(12): 3624-3635.

85. Rotger, R. and Casadesüs, J. (1999) The virulence plasmids of Salmonella. Int Microbiol., 2(3): 177-184.

86. Ahmer, B.M.M., Tran, M. and Heffron, F. (1999) The virulence plasmid of Salmonella Typhimurium is self-transmissible. J. Bacteriol., 181(4): 1364-1368.

87. Foley, S.L., Johnson, T.J., Ricke, S.C., Nayak, R. and Danzeisen, J. (2013) Salmonella pathogenicity and host adaptation in chicken-associated serovars. Microbiol. Mol. Biol. Rev., 77(4): 582-607.

88. Han, J., Lynne, A.M., David, D.E., Tang, H., Xu, J., Nayak, R., Kaldhone, P., Logue, C.M. and Foley, S.L. (2012) DNA sequence analysis of plasmids from multidrug-resistant Salmonella enterica serotype Heidelberg isolates. PLoS One, 7(12): e51160.

89. Johnson, T.J., Thorsness, J.L. and Anderson CP, Williams, D. and Gogarten, J.P. (2010) Horizontal gene transfer of a colV plasmid has resulted in a dominant avian clonal type of Salmonella enterica serovar Kentucky. PLoS One, 5(12): e15524.

90. Ashkenazi, S., Cleary, T.G., Murray, B.E., Wanger, A. and Pickering, L.K. (1988) Quantitative analysis and partial characterization of cytotoxin production by Salmonella strains. Infect. Immun., 56(12): 3089-3094.

91. Prager, R., Fruth, A. and Tschape, H. (1995) Salmonella enterotoxin (stn) gene is prevalent among strains of Salmonella enterica, but not among Salmonella bongori and other Enterobacteriaceae. FEMS Immunol. Med. Microbiol., 12(1): 47-50.

92. Dehoux, P. and Cossart, P. (1995) Homologies between salmolysin and some bacterial regulatory proteins. Mol. Microbiol., 15(3): 591-592.

93. Kasturi, P.K., Panigrahi, D., Ganguly, N.K., Nayak, N., Ayyagari, A. and Khuller, M. (1991) Enterotoxin production and mouse virulence of clinical isolates of Salmonella Typhimurium strains. Indian J. Med. Res., 93(1): 166-170.

94. Morales, E.R.M., Gonzalez-Valencia, G., Munoz, O. and Torres, J (1993) Production of cytotoxins and enterotoxins by strains of Shigella and Salmonella isolated from children with bloody diarrhea. Arch. Med. Res., 24(1): 13-21.

95. Malik, P., Sharma, V.D. and Chandra, R. (1995) Cytotoxigenicity in Salmonella serovars. Indian J. Exp. Biol., 33(3): 177-181.

96. Rumeu, M.T., Suárez, M.A., Morales, S. and Rotger, R. (1997) Enterotoxin and cytotoxin production by Salmonella Enteritidis strains isolated from gastroenteritis outbreaks. $J$. Appl. Microbiol., 82(1): 19-31.

97. Ansong, C., Yoon, H., Norbeck, A.D., Gustin, J.K., McDermott, J.E., Mottaz, H.M., Rue, J., Adkins, J.N., Heffron, F. and Smith, R.D. (2008) Proteomics analysis of the causative agent of typhoid fever. J. Proteome Res., 7(2): 546-557.

98. Parker, M.W. and Feil, S.C. (2005) Pore-forming protein toxins: From structure to function. Prog. Biophys. Mol. Biol., 88(1): 91-142.

99. Agrawal, R.K., Singh, B.R., Babu, N. and Chandra, M (2005) Novel haemolysins of Salmonella enterica spp. enterica serovar Gallinarum. Indian J. Exp. Biol., 43(7): 626-630.

100. Shamma, F., Ahsan, N., Mj, I. and Ahsan, C.R. (2016) Environmental factors regulate the hlye gene expression in both $S$. Typhi and $E$. coli in a similar way to display haemolytic activity. Bangladesh Med. Res. Counc. Bull., 42(1): 33-38.

101. Singh, B.R., Singh, V.P., Agarwal, M., Sharma, G. and Chandra, M. (2004) Haemolysins of Salmonella, their role in pathogenesis and subtyping of Salmonella serovars. Indian J. Exp. Biol., 42(3): 303-313.

102. Dufresne, K. and Daigle, F. (2017) Salmonella fimbriae: What is the clue to their hairdo? In: Current Topics in Salmonella and Salmonellosis. InTechOpen, London. p59-79.

103. Dufresne, K., Saulnier-Bellemare, J. and Daigle, F. (2018) Functional analysis of the chaperone-usher fimbrial gene clusters of Salmonella enterica serovar Typhi. Front. Cell. Infect. Microbiol., 8: 26.

104. Humphries, A.D., Raffatellu, M., Winter, S., Weening, E.H., Kingsley, R.A., Droleskey, R., Zhang, S., Figueiredo, J., Khare, S., Nunes, J., Adams, L.G., Tsolis, R.M. and Bäumler, A.J. (2003) The use of flow cytometry to detect expression of subunits encoded by 11 Salmonella enterica serotype Typhimurium fimbrial operons. Mol. Microbiol., 48(5): 1357-1376.

105. Townsend, S.M., Kramer, N.E., Edwards, R., Baker, S., Hamlin, N., Simmonds, M., Stevens, K., Maloy, S., Parkhill, J., Dougan, G. and Bäumler, A.J. (2001) Salmonella enterica serovar Typhi possesses a unique repertoire of fimbrial gene sequences. Infect. Immun., 69(5): 2894-2901.

106. Nuccio, S. and Baumler, A. (2007) Evolution of the chaperone/usher assembly pathway: Fimbrial classification goes Greek. Microbiol. Mol. Biol. Rev., 71(4): 551-575.

107. Mol, O. and Oudega, B. (1996) Molecular and structural aspects of fimbriae biosynthesis and assembly in Escherichia coli. FEMS Microbiol. Rev., 19(1): 25-52.

108. Harris, J.B., Baresch-Bernal, A., Rollins, S.M., Alam, A., LaRocque, R.C., Bikowski, M., Peppercorn, A.F., Handfield, M., Hillman, J.D., Qadri, F., Calderwood, S.B., Hohmann, E., Breiman, R.F., Brooks, W.A. and Ryan, E.T. (2006) Identification of in vivo-induced bacterial protein antigens during human infection with Salmonella enterica serovar Typhi. Infect. Immun., 74(9): 5161-5168.

109. Boddicker, J.D., Ledeboer, N.A., Jagnow, J., Jones, B.D. and Clegg, S. (2002) Differential binding to and biofilm formation on HEp-2 cells by Salmonella enterica serovar Typhimurium is dependent upon allelic variation in the fimH gene of the fim gene cluster. Mol. Microbiol., 45(5): $1255-1265$.

110. Edwards, R.A., Schifferli, D.M. and Maloy, S.R. (2000) A role for Salmonella fimbriae in intraperitoneal infections. Proc. Natl. Acad. Sci., 97(3): 1258-1262.

111. Chessa, D., Winter, M.G., Jakomin, M. and Bäumler, A.J. (2009) Salmonella enterica serotype Typhimurium std fimbriae bind terminal $\alpha(1,2)$ fucose residues in the cecal mucosa. Mol. Microbiol., 71(4): 864-875.

112. Humphries, A., Deridder, S. and Bäumler, A.J. (2005) Salmonella enterica serotype Typhimurium fimbrial proteins serve as antigens during infection of mice. Infect. Immun., 73(9): 5329-5338.

113. Weening, E.H., Barker, J.D., Laarakker, M.C., Humphries, A.D., Tsolis, R.M. and Bäumler, A.J. (2005) The Salmonella enterica serotype Typhimurium lpf, bcf, stb, stc, std, and sth fimbrial operons are required for intestinal persistence in mice. Infect. Immun., 73(6): 3358-3366.

114. Yue, M., Han, X., De Masi, L., Zhu, C., Ma, X., Zhang, J., Wu, R., Schmieder, R., Kaushik, R.S., Fraser, G.P., Zhao, S., McDermott, P.F., Weill, F.X., Mainil, J.G., Arze, C., Fricke, W.F., Edwards, R.A., Brisson, D., Zhang, N.R., Rankin, S.C. and Schifferli, D.M. (2015) Corrigendum: Allelic variation contributes to bacterial host specificity. Nat Commun., 6(2015): 8754.

115. Turner, A.K., Lovell, M.A., Hulme, S.D., Zhang-Barber, L. and Barrow, P.A. (1998) Identification of Salmonella Typhimurium genes required for colonization of the chicken alimentary tract and for virulence in newly hatched chicks. Infect. Immun., 66(5): 2099-2106.

116. Morgan, E., Campbell, J.D., Rowe, S.C., Bispham, J., Stevens, M.P., Bowen, A.J., Barrow, P.A., Maskell, D.J. and Wallis, T.S. (2004) Identification of host-specific colonization factors of Salmonella enterica serovar Typhimurium. Mol. Microbiol., 54(4): 994-1010.

117. Carnell, S.C., Bowen, A., Morgan, E., Maskell, D.J., Wallis, T.S. and Stevens, M.P. (2007) Role in virulence and protective efficacy in pigs of Salmonella enterica 
serovar Typhimurium secreted components identified by signature-tagged mutagenesis. Microbiology, 153(Pt6): 1940-1952.

118. Gantois, I., Ducatelle, R., Pasmans, F., Haesebrouck. F., Hautefort, I., Thompson, A., Hinton, J.C. and Van Immerseel, F. (2006) Butyrate specifically down-regulates Salmonella pathogenicity island 1 gene expression. Appl. Environ. Microbiol., 72(1): 946-949.

119. Evangelopoulou, G., Kritas, S., Govaris, A. and Burriel, A.R. (2013) Animal salmonelloses: A brief review of "host adaptation and host specificity" of Salmonella spp. Vet. World, 6(10): 703-708.

120. Uzzau, S., Leori, G.S., Petruzzi, V., Watson, P.R., Schianchi, G., Bacciu, D., Mazzarello, V., Wallis, T.S. and Rubino, S. (2001) Salmonella enterica serovar-host specificity does not correlate with the magnitude of intestinal invasion in sheep. Infect. Immun., 69(5): 3092-3099.

121. Kingsley, R.A. and Bäumler, A.J. (2000) Host adaptation and the emergence of infectious disease: The Salmonella paradigm. Mol. Microbiol., 36(5): 1006-1014.

122. Kisiela, D.I., Chattopadhyay, S., Libby, S.J, Karlinsey, J.E., Fang, F.C., Tchesnokova, V., Kramer, J.J., Beskhlebnaya, V., Samadpour, M., Grzymajlo, K., Ugorski, M., Lankau, E.W., Mackie, R.I., Clegg, S. and Sokurenko, E.V. (2012) Evolution of Salmonella enterica virulence via point mutations in the fimbrial adhesin. PLoS Pathog., 8(6): e1002733.

123. Rabsch, W., Andrews, H.L., Kingsley, R.A., Prager, R., Tschäpe, H., Adams, L.G. and Bäumler, A.J. (2002) Salmonella enterica serotype Typhimurium and its hostadapted variants. Infect. Immun., 70(5): 2249-2255.

124. Heithoff, D.M., Shimp, W.R., Lau, P.W., Badie, G., Enioutina, E.Y., Daynes, R.A., Byrne, B.A., House, J.K. and Mahan, M.J. (2008) Human Salmonella clinical isolates distinct from those of animal origin. Appl. Environ. Microbiol., 74(6): 1757-1766.

125. Paulin, S.M., Watson, P.R., Benmore, A.R., Stevens, M.P., Jones, P.W., Villarreal-Ramos, B. and Wallis, T.S. (2002) Analysis of Salmonella enterica serotype-host specificity in calves: Avirulence of S. enterica serotype Gallinarum correlates with bacterial dissemination from mesenteric lymph nodes and persistence in vivo. Infect. Immun., 70(12): 6788-6797.

126. Xu, T., Maloy, S., McGuire, K.L. (2009) Macrophages influence Salmonella host-specificity in vivo. Microb. Pathog., 47(4): 212-222.

127. Singh, B.R. (2013) Effect of aroA, htrA and aroA-htrA deletion mutation on ability of Salmonella Abortusequi to survive and multiply in macrophages. Available from: https://www.notoare.com/index.php/index/explorer/getNoto/10864328. Last accessed on 27-03-2019

128. Bäumler, A.J., Tsolis, R.M., Ficht, T.A. and Adams, L.G. (1998) Evolution of host adaptation in Salmonella enterica. Infect. Immun., 66(10): 4579-4587.

129. Su, L.H. and Chiu, C.H. (2007) Salmonella: Clinical importance and evolution of nomenclature. Chang Gung Med. J., 30(3): 210-219.

130. Rebecca, Z.S. and Andrea, M.A. (2017) Preharvest Salmonella risk contamination and the control strategies. In: Current Topics in Salmonella and Salmonellosis. InTechOpen, London. p193-213.

131. Poppe, C., Johnson, R.P., Forsberg, C.M. and Irwin, R.J. (1992) Salmonella Enteritidis and other Salmonella in laying hens and eggs from flocks with Salmonella in their environment. Can. J. Vet. Res., 56(3): 226-232.

132. Andres, V.M. and Davies, R.H. (2015) Biosecurity measures to control Salmonella and other infectious agents in pig farms: A review. Compr. Rev. Food Sci. Food Saf., 14(4): 317-335.

133. Gow, A.G., Gow, D.J., Hall, E.J., Langton, D., Clarke, C. and Papasouliotis, K. (2009) Prevalence of potentially pathogenic enteric organisms in clinically healthy kittens in the UK. J. Feline Med. Surg., 11(8): 655-662.
134. Hanson, D.L., Loneragan, G.H., Brown, T.R., Nisbet, D.J., Hume, M.E. and Edrington, T.S. (2016) Evidence supporting vertical transmission of Salmonella in dairy cattle. Epidemiol. Infect., 144(5): 962-967.

135. Xu, Y., Tao, S., Hinkle, N., Harrison, M. and Chen, J. (2018) Salmonella, including antibiotic-resistant Salmonella, from flies captured from cattle farms in Georgia, U.S.A. Sci. Total Environ., 616-617(2018): 90-96.

136. Choo, L.C., Saleha, A.A., Wai, S.S. and Fauziah, N. (2011) Isolation of Campylobacter and Salmonella from houseflies (Musca domestica) in a university campus and a poultry farm in Selangor, Malaysia. Trop. Biomed., 28(1): 16-20.

137. Parvez, M.A.K., Marzan, M., Khatun, F., Ahmed, M.F., Mahmud, S.A. and Rahman, S.R. (2016) Isolation of multidrug-resistant pathogenic bacteria from common flies in Dhaka, Bangladesh. J. Entomol., 13(4): 141-147.

138. Ommi, D., Hemmatinezhad, B., Hafshejani, T.T. and Khamesipour, F. (2017) Incidence and antimicrobial resistance of Campylobacter and Salmonella from houseflies (Musca domestica) in kitchens, farms, hospitals and slaughterhouses. Proc. Natl. Acad. Sci. India Sect. B. Biol. Sci., 87(4): 1285-1291.

139. Kich, J.D., Mores, N., Piffer, I.A., Coldebella, A., Amaral, A., Ramminger, L. and Cardoso, M. (2005) Factors associated with seroprevalence of Salmonella in commercial pig herds. Ciência Rural, 35(2): 398-405.

140. Byarugaba, D.K. (2010) Mechanisms of antimicrobial resistance. In: Sosa, A.J., editor. Antimicrobial Resistance in Developing Countries. Springer Science +Business Media, Berlin. p15-27.

141. Ventola, C.L. (2015) The antibiotic resistance crisis: Part 1: Causes and threats. $P T, 40(4): 277-283$.

142. World Health Organization. (2015) Global Action Plan on Antimicrobial Resistance. World Health Organization, Geneva.

143. Jelalu, K., Berhanu, S., Sissay, M., Yitagele, T. and Yimer, M. (2015) Antimicrobial resistance patterns of Salmonella in Ethiopia: A review. Afr. J Microbiol. Res., 9(46): 2249-2256.

144. FAO. (2015) Status Report on Antimicrobial Resistance. Food and Agriculture Organization of the United Nations, Rome.

145. Founou, L.L., Founou, R.C. and Essack, S.Y. (2016) Antibiotic resistance in the food chain: A developing country-perspective. Front. Microbiol., 7 : Article no.1881.

146. Araque, M. (2009) Nontyphoid Salmonella gastroenteritis in pediatric patients from urban areas in the city of Mérida, Venezuela. J. Infect. Dev. Ctries., 3(1): 28-34.

147. Hur, J., Choi, Y.Y., Park, J.H., Jeon, B.W., Lee, H.S., Kim, A.R. and Lee, J.H. (2011) Antimicrobial resistance, virulence-associated genes, and pulsed-field gel electrophoresis profiles of Salmonella enterica subsp. enterica serovar Typhimurium isolated from piglets with diarrhea in Korea. Can. J. Vet. Res., 75(1): 49-56.

148. Singh, S., Yadav, A.S., Singh, S.M. and Bharti, P. (2010) Prevalence of Salmonella in chicken eggs collected from poultry farms and marketing channels and their antimicrobial resistance. Food Res. Int., 43(8): 2027-2030.

149. García-Feliz, C., Collazos, J.A., Carvajal, A., Herrera, S., Echeita, M.A. and Rubio, P. (2008) Antimicrobial resistance of Salmonella enterica isolates from apparently healthy and clinically ill finishing pigs in Spain. Zoonoses Public Health, 55(4): 195-205.

150. Niranjan, H.B. and Bhaskar, M.M. (2017) Drug resistance in nontyphoidal Salmonella - challenges for the future. J. Vet. Med. Res., 4(4).

151. Chang, Q., Wang, W., Regev-Yochay, G., Lipsitch, M. and Hanage, W.P. (2015) Antibiotics in agriculture and the risk to human health: How worried should we be? Evol. Appl., 8(3): 240-245.

152. Da Costa, P.M., Loureiro, L. and Matos, A.J.F. (2013) Transfer of multi-drug resistant bacteria between 
intermingled ecological niches: The interface between humans, animals and the environment. Int. J. Environ. Res. Public Health, 10(1): 278-294.

153. Al Bayssari, C., Dabboussi, F., Hamze, M. and Rolain, J.M. (2015) Emergence of carbapenemase-producing Pseudomonas aeruginosa and Acinetobacter baumannii in livestock animals in Lebanon. J. Antimicrob. Chemother., 70(3): 950-951.

154. Fischer, J., Rodriguez, I., Schmoger, S., Friese, A., Roesler, U., Helmuth R, Guerra, B. (2012) Escherichia coli producing VIM-1 carbapenemase isolated on a pig farm. J. Antimicrob. Chemother., 67(7): 1793-1795.

155. Bae, D., Cheng, C.M. and Khan, A.A. (2015) Characterization of extended-spectrum $\beta$-lactamase (ESBL) producing non-typhoidal Salmonella (NTS) from imported food products. Int. J. Food Microbiol., 214(2015): 12-17.

156. Liu, Y.Y., Wang, Y., Walsh, T.R., Yi, L.X., Zhang, R., Spencer, J., Doi, Y., Tian, G., Dong, B., Huang, X., Yu, L.F., Gu, D., Ren, H., Chen, X., Lv, L., He, D., Zhou, H., Liang, Z., Liu, J.H. and Shen, J. (2016) Emergence of plasmid-mediated colistin resistance mechanis mmcr 1 in animals and human beings in China: A microbiological and molecular biological study. Lancet Infect. Dis., 16(2): 161-168.

157. Ren, D., Chen, P., Wang, Y., Wang, J., Liu, H. and Liu, H. (2017) Phenotypes and antimicrobial resistance genes in Salmonella isolated from retail chicken and pork in Changchun, China. J. Food Saf., 37(2): e12314.

158. Montville, T. and Matthews, K. (2008) Food Microbiology: An Introduction. $2^{\text {nd }}$ ed. ASM Press, Washington, USA.

159. Yoke-Kqueen. C., Learn-Han, L., Noorzaleha, A.S., Son, R., Sabrina, S., Jiun-Horng, S. and Chai-Hoon, K. (2008) Characterization of multiple-antimicrobial-resistant Salmonella enterica subsp. enterica isolated from indigenous vegetables and poultry in Malaysia. Lett. Appl. Microbiol., 46(3): 318-324.

160. Singh, R., Yadav, A.S., Tripathi, V. and Singh, R.P. (2013) Antimicrobial resistance profile of Salmonella present in poultry and poultry environment in North India. Food Control, 33(2): 545-548.

161. Asai, T., Namimatsu, T., Osumi, T., Kojima, A., Harada, K., Aoki, H., Sameshima, T. and Takahashi, T. (2010) Molecular typing and antimicrobial resistance of Salmonella enterica subspecies serovar Choleraesuis isolates from diseased pigs in Japan. Comp. Immunol. Microbiol. Infect. Dis., 33(2): 109-119.

162. Singh, B.R. (2012) Prevalence of multiple drug-resistant Salmonella and E. coli in table eggs in North India. Available from: https://www.notoare.com/index.php/index/ explorer/getNoto/11636071. Last accessed on 27-03-2019.

163. Ahmed, A.M., Shimamoto, T. and Shimamoto, T. (2014) Characterization of integrons and resistance genes in multidrug-resistant Salmonella enterica isolated from meat and dairy products in Egypt. Int. J. Food Microbiol., 189(2014): 39-44.

164. Rotimi, V.O., Jamal, W., Pal, T., Sovenned, A. and Albert, M.J. (2008) Emergence of CTX-M-15 type extended-spectrum $\beta$-lactamase-producing Salmonella spp. in Kuwait and the United Arab Emirates. J. Med. Microbiol., 57(Pt 1): 881-886.

165. Garedew, L., Hagos, Z., Addis, Z., Tesfaye, R. and Zegeye, B. (2015) Prevalence and antimicrobial susceptibility patterns of Salmonella isolates in association with hygienic status from butcher shops in Gondar town, Ethiopia. Antimicrob. Resist. Infect. Control, 4: 21.

166. Moe, A.Z., Paulsen, P., Pichpol, D., Fries, R., Irsigler, H., Baumann, M.P.O. and Oo, K.N. (2017) Prevalence and antimicrobial resistance of Salmonella isolates from chicken carcasses in retail markets in Yangon, Myanmar. J. Food Prot., 80(6): 947-951.

167. Karp, B.E., Tate, H., Plumblee, J.R, Dessai, U., Whichard, J.M., Thacker, E.L., Hale, K.R., Wilson, W., Friedman, C.R. and Griffin, P.M. (2017) National antimicrobial resistance monitoring system: Two decades of advancing public health through integrated surveillance of antimicrobial resistance. Foodborne Pathog. Dis., 14(10): 545-557.

168. FDA. (2010) National Antimicrobial Monitoring SystemEnteric Bacteria (NARMS): 2007 Executive Summary Report. U.S. Department of Health and Human Services, US Food and Drug Administration, Rokville, MD.

169. NARMS. (2013) NARMS Report for Human Isolates Final Report. National Center for Emerging and Zoonotic Infectious Disease, Atlanta, USA.

170. Hur, J., Jawale, C. and Lee, J.H. (2012) Antimicrobial resistance of Salmonella isolated from food animals: A review. Food Res. Int., 45(2): 819-830.

171. Zhao, S., White, D.G., Friedman, S.L., Glenn, A., Blickenstaff, K., Ayers, S.L., Abbott, J.W., HallRobinson, E. and McDermott, P.F. (2008) Antimicrobial resistance in Salmonella enterica serovar Heidelberg isolates from retail meats, including poultry, from 2002 to 2006. Appl. Environ. Microbiol., 74(21): 6656-6662.

172. Brisabois, A., Cazin, I., Breuil, J. and Collatz, E. (1997) Surveillance of antibiotic resistance in Salmonella. Eurosurveillance, 2(3): 19-20.

173. Voogd, C.E., van Leeuwen, W.J., Guinée, P.A., Manten, A. and Valkenburg, J.J. (1977) Incidence of resistance to ampicillin, chloramphenicol, kanamycin and tetracycline among Salmonella species isolated in the Netherlands in 1972, 1973 and 1974. Antonie Van Leeuwenhoek, 43(3-4): 269-281.

174. Folster, J.P., Pecic, G., Singh, A, Duval, B., Rickert, R., Ayers, S., Abbott, J., McGlinchey, B., Bauer-Turpin, J., Haro, J., Hise, K., Zhao, S., Fedorka-Cray, P.J., Whichard, J. and McDermott, P.F. (2012) Characterization of extended-spectrum cephalosporin-resistant Salmonella enterica serovar Heidelberg isolated from food animals, retail meat, and humans in the United States 2009. Foodborne Pathog. Dis., 9(7): 638-645.

175. Threlfall, E.J., Frost, J.A., Ward, L.R., Rowe, B. (1996) Increasing spectrum of resistance in multiresistant Salmonella Typhimurium. Lancet, 347(9007): 1053-1054.

176. Gebreyes, W.A., Thakur, S., Davies, P.R., Funk, J.A. and Altier, C (2004) Trends in antimicrobial resistance, phage types and integrons among Salmonella serotypes from pigs, 1997-2000. J. Antimicrob. Chemother., 53(6): 997-1003.

177. Rayamajhi, N., Kang, S.G., Kang, M.L., Lee, H.S., Park, K.Y. and Yoo, H.S. (2008) Assessment of antibiotic resistance phenotype and integrons in Salmonella enterica serovar Typhimurium isolated from swine. J. Vet. Med. Sci., 70(10): 1133-1137.

178. Chen, S., Zhao, S., White, D.G., Schroeder, C.M., Lu, R., Yang, H., McDermott, P.F., Ayers, S. and Meng, J. (2004) Characterization of multiple-antimicrobial-resistant Salmonella serovars isolated from retail meats. Appl. Environ. Microbiol., 70(1): 1-7.

179. Tauxe, R.V., Doyle, M.P., Kuchenmüller, T., Schlundt, J. and Stein, C.E. (2010) Evolving public health approaches to the global challenge of foodborne infections. Int. J. Food Microbiol., 139(1): 16-28.

180. Olobatoke, R.Y. (2017) Public health burden of non-typhoidal Salmonella strains in sub-Saharan Africa. Int. Res. J. Public Environ. Health, 4(6): 112-119.

181. Saravanan, S., Purushothaman, V., Ramasamy, T., Krishna, G., Sukumar, K., Srinivasan, P., Gowthaman, V., Balusamy, M., Atterbury, R. and Kuchipudi, S.V. (2015) Molecular epidemiology of nontyphoidal Salmonella in poultry and poultry products in India: Implications for human health. Indian J. Microbiol., 55(3): 319-326.

182. Crump, J.A., Luby, S.P. and Mintz, E.D. (2004) The global burden of typhoid fever. Bull. World Health Organ., 82(5): 346-353.

183. Langridge, G.C., Wain, J. and Nair, S. (2012) Invasive salmonellosis in humans. EcoSal Plus, 5(1). 
184. Galanis, E., Fo Wong, D.M.A., Patrick, M.E., Binsztein, N., Cieslik, A., Chalermchaikit, T., Aidara-Kane, A., Ellis, A., Angulo, F.J. and Wegener, H.C. (2006) Web-based surveillance and global Salmonella distribution, 2000-2002. Emerg. Infect. Dis., 12(3): 381-388.

185. USDA. (2013) Foodborne Illness Cost Calculator: Salmonella. Available from: https://www.ers.usda.gov/ amber-waves/2013/november/recent-estimates-of-thecost-of-foodborne-illness-are-in-general-agreement. Last accessed on 07-11-2017.

186. Taitt, C.R., Shubin, Y.S., Angel, R. and Ligler, F.S. (2004) Detection of Salmonella enterica serovar Typhimurium by using a rapid, array-based immunosensor. Appl. Environ. Microbiol., 70(1): 152-158.

$* * * * * * * *$ 